Article

\title{
High-Efficiency Determination of Coastline by Combination of Tidal Level and Coastal Zone DEM from UAV Tilt Photogrammetry
}

\author{
Chao Huang ${ }^{1}$, Hongmei Zhang ${ }^{2, *}$ and Jianhu Zhao ${ }^{1}$ \\ 1 School of Geodesy and Geomatics, Wuhan University, No. 129 Luoyu Road, Wuhan 430079, China; \\ 2014301610145@whu.edu.cn (C.H.); jhzhao@whu.edu.cn (J.Z.) \\ 2 Department of Artificial Intelligence and Automation, School of Electrical Engineering and Automation, \\ Wuhan University, No. 8 Donghu Southern Road, Wuhan 430072, China \\ * Correspondence: hmzhang@whu.edu.cn; Tel.: +86-137-9708-8532
}

Received: 24 May 2020; Accepted: 6 July 2020; Published: 8 July 2020

\begin{abstract}
To meet the needs of coastline efficient extraction and dynamic monitoring, this paper proposes a new method for coastline extraction by combining the tidal level and the digital elevation model (DEM) of the coastal zone from tilt photography. Firstly, the DEM of coastal zone was obtained by using unmanned aerial vehicle (UAV) tilt photography; at the same time, the accuracy of aerial triangulation(AT) is improved referencing to the constraint of water boundary points, and then the mean high water spring tide was obtained by combining tidal harmonic analysis and Global Navigation Satellite System (GNSS) tidal level. Finally, the coastline and the dynamic water-surface line are extracted from the DEM of the coastal zone by tracking the contour lines with the elevation of the mean high water springs (MHWS) and the instantaneous sea-surface elevation, respectively. The experiments carried out in the coastal zones of Liaoning Province, China, proved the proposed method and achieved better than $0.2 \mathrm{~m}$ of horizontal position accuracy and $0.1 \mathrm{~m}$ of the vertical accuracy.
\end{abstract}

Keywords: coastline monitoring and management; coastal zone digital elevation model (DEM); mean high water springs (MHWS); tilt photography; GNSS tidal measurement

\section{Introduction}

The coastline is the boundary line between sea and land for dividing marine area and terrestrial administrative area [1]. Measuring and monitoring coastline change is a very important and fundamental task for coastal zone management [2], and it is a major environmental safety issue for humans, such as sea level changes [3] and coastal zone evolution [4]. At the same time, the shoreline change, as one of the important parameters of various Coastal Vulnerability Indices, plays an important role in assessing the physical vulnerability of the coasts to the anticipated sea-level rise and to the climate-change related coastal hazards, such as storm surges [5-8].

At present, the determination and dynamic monitoring of coastline are mostly carried out by the traditional field investigation method [9] and the remote sensing techniques, such as satellite imaging, aerial photogrammetry measurement, or light detection and ranging (LiDAR) measurement [10]. The field investigation method requires surveyors to arrive at the field and judge the positions of coastlines based on the trace lines formed by the erosions of high tide level on coastal zones, which is time-consuming, laborious, and various due to different manual experiences [9]. The satellite image is often used to extract instantaneous water edges of the sensor imaging time by the distinction or dried coastal zone and water surface images [11], as well as the extractions of the coastline by the image difference of eroded coastal zone and non-eroded one [12]. The extraction method is limited by factors, 
such as image resolution, meteorological conditions, and satellite revisiting period, and difficultly guarantees the timeliness and accuracy of the extractions [11,13]. As for the extraction method, the artificial discrimination has to be adopted due to blurred satellite images and complex coastal zone and unavoidably brings time-consuming and laborious [14]. Compared with the satellite remote sensing method, LiDAR can acquire precise topographic information and determine coastline position combining tidal information [15], which can be measured repeatedly. Moreover, the uncertainties of LiDAR are often much smaller than traditional methodologies [16]. Over the past decade, with the availability and widespread use of digital photogrammetric cameras, photogrammetry has become an important solution for coastal monitoring and may be a more economical solution. Photogrammetric means can obtain high-precision digital orthophoto map (DOM) and digital elevation model (DEM) results. However, due to the limitation of poor texture features in coastal areas, DEM results have poor accuracy. DOM results are often used to extract trace lines formed by spring tide erosion in a short period based on image features, resulting in large differences in the location of multi-stage results, and the accuracy is easily affected by the bottom material attributes of the coastline area. The method has poor repeatability and applicability [17-19]. As a high and new technology in surveying and mapping field, the unmanned aerial vehicle (UAV) tilt photogrammetry technology has the characteristics of low cost, high efficiency, portability, and high precision in obtaining spatial three-dimensional information, and has also been proven to be suitable for high-precision mapping and monitoring of topographic and geomorphological changes in coastal zones that are not suitable for traditional photogrammetry [20]. Gonçalves and Henriques [21] used the UAV tilt photography technology to obtain the digital surface models (DSM) and digital elevation models with better than $10 \mathrm{~cm}$ of vertical accuracy in different terrains. Although the UAV tilt photogrammetry is relatively infrequently used for coastal monitoring currently [22-31], it does provide a new high-efficiency and low-cost way to get the DEM of the coastal zone for the determination of the coastline, as well as richer terrain and texture information compared with traditional vertical photogrammetry.

The definition of a coastline as the boundary between land and sea has always been different, but the tidal datum is generally used as the standard to describe the coastline [32], which varies according to the tidal type. The National Oceanic Atmospheric Administration (NOAA) uses mean high water and mean low water to determine the boundary between land and sea [33], and Spain uses mean sea level to determine the coastline [34]. In China, the coastline is defined by the mean high water spring tide (MHWS). MHWS is obtained by averaging all of the high tide levels in a long period [35]. Long-term tidal gauges always distribute sparsely along the coast shore and difficultly meet with the determination of the MHWS and the instantaneous tidal level at the coastal zone without or far from long-term tidal gauges. Global sea tidal models, such as NAO.99b, CSR4.0, GOT00, TPXO7.2, FES2004, and EOT10a, can provide main tidal constituents for calculating MHWS by the theoretic model [36] and have higher accuracies in deep ocean and low accuracies in shallow water region due to the various tide induced by complex coastal terrain [37]. Therefore, it becomes more difficult to get accurate MHWS and instantaneous tidal level for the determinations of the coastline and the instantaneous sea water line. At a long-term tidal gauge, the main tidal constituents can be provided by the optimum global sea tidal model and the long-series tidal data [38], and the latter has high accuracy and can be used for revising the former and improving the accuracies of these main tidal constituents from the former for determining MHWS. Besides, the residual water level can be obtained by the difference between the tidal level measured at the tidal gauge and that from the tidal model, as well as be used for improving the forecast tidal level of the tidal model [39]. These methods imply that MHWS and the instantaneous tidal level can be obtained along coastal zone by integration of the global sea tidal model and the tidal level of temporal tidal gauge.

To efficiently get high-accuracy coastline, this paper proposes a new method by combining the tide information and the coast zone DEM from UAV tilt photography. The paper is structured as follows: Section 2 elaborates the data acquisition and the proposed method, including the study area, field measurement, a comprehensive method for determining the MHWS and the instantaneous 
tidal level at an inshore water by combining the long-term tidal level, the global sea tidal model and the Global Navigation Satellite System (GNSS) tidal level, an improved waterline-constraint UAV tilt photography method for getting the DEM in poor-characteristic coast zone, and a superposition method for determining the final coastline. Section 3 analyzes the experimental results of the two regions in Liaoning in detail and verifies. Section 4 discusses the performance of proposed method. Finally, some conclusions and recommendations are drawn out in Section 5.

\section{Materials and Methods}

This paper proposes a new method for coastline determination. The process is depicted as follows and is shown in Figure 1:

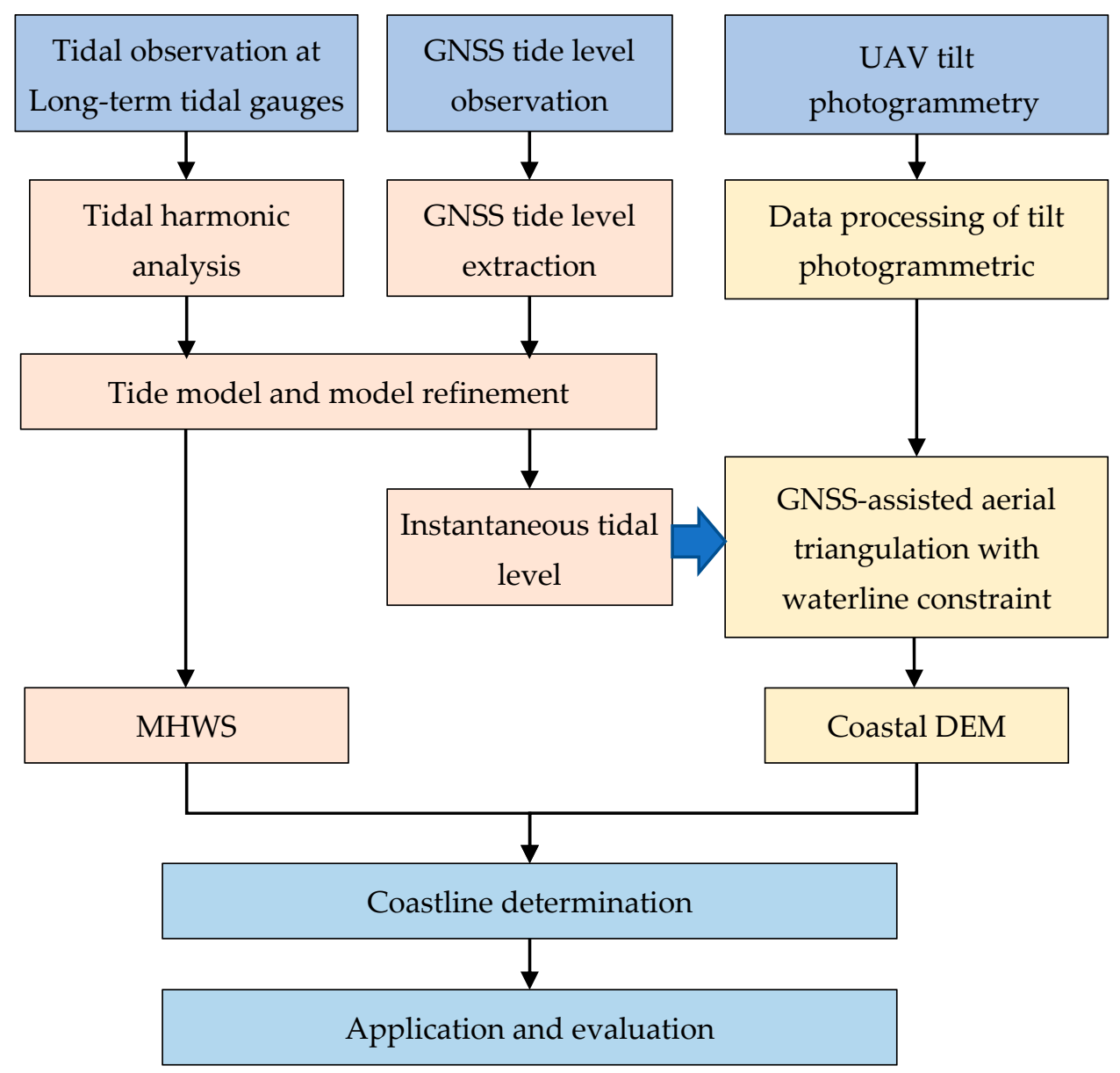

Figure 1. Flowchart of the method obtaining the coastline.

Step 1: Data acquisition. In a coastal zone, the images of the coastal zone are obtained by the UAV tilted photography, the real-time tidal level is observed by a mounted-GNSS unmanned ship, and the long-term tidal data is extracted from these neighbor tidal gauges.

Step 2: Determinations of MHWS and real-time waterline. By the long-term tidal data, the tidal harmonic analysis is done to obtain the tidal model, and the MHWS is determined by the established tidal model. Moreover, the real-time tidal level and waterline are obtained accurately through correcting the tidal model by GNSS tidal level.

Step 3: Acquisition of the coastal DEM. The GNSS-assisted UAV tilt photography data is processed to obtain coastal DEM by the proposed waterline-constraint aerial triangulation.

Step 4: Coastline determination. With the help of ESRI's ArcGIS software (Redlands CA, USA), the coastline is determined by combining the coastal DEM and the determined MHWS. 
Step 5: Applications and evaluations. The proposed method is used for the coastline determinations of two study areas, as well as evaluated qualitatively and quantitatively in these applications.

\subsection{Study Area}

To verify the feasibility of the proposed method, two areas with different coastal types, sediments and tides in Liaoning province, China, named LN-A and LN-B (Figure 2), were selected and measured in 2017. LN-A closes to Yingkou City and is composed of artificial fishery breeding grounds (Figure 2b), beaches, and artificial embankments and includes scarce vegetation and sands. LN-B closes to Dalian city and is composed of gravel shore (Figure 2c), beaches, and cliffs and has rich vegetation and gravel, bedrock, and sands. LN-A is influenced by frequent human activities, including a large number of buildings and human footprints. LN-B is rarely affected by human activities and contains a large number of cliffs and woods. Besides, the two areas have common characteristics, such as narrow beach and obvious trace lines. Therefore, the two areas are representative for testing our proposed method.

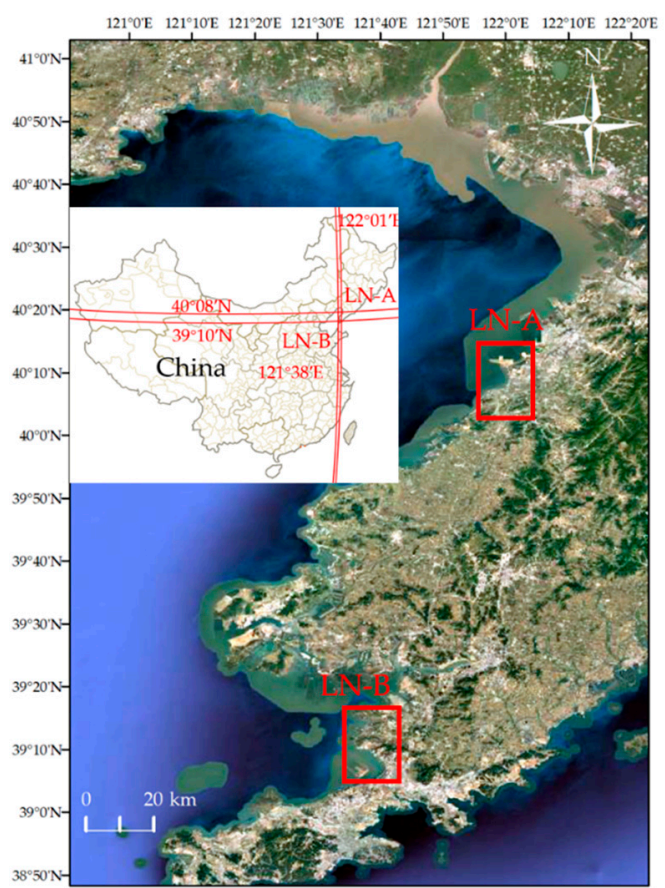

(a)

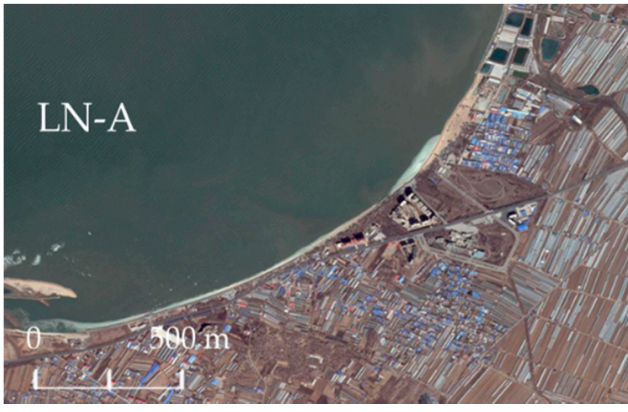

(b)

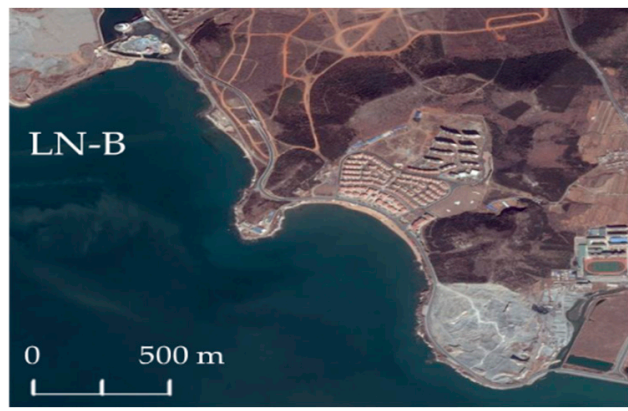

(c)

Figure 2. Landsat images of the study areas. (a) Landsat images of the two study areas and their locations in the map of China. (b) Landsat image of LN-A. (c) Landsat image of the LN-B.

\subsection{Field Measurements}

\subsubsection{Data Collection of Tilt Photography}

In this measurement, the UAV measuring system equipped with Sony tilt camera, POS/AV system (POS system produced by Applanix company) and aerial camera control system was adopted. The eccentricity vector of Global Positioning System (GPS) antenna phase center and camera photography center has been measured by the calibration field. We used a Sony rx1rm2 five lens camera with a $35 \mathrm{~mm}$ focal length, $7952 \times 5304$ pixels image amplitude, $35.9 \times 24 \mathrm{~mm}$ Charge Coupled Device/Complementary Metal Oxide Semiconductor (CCD/CMOS) sensor, and $0.00451 \mathrm{~mm}$ pixel. To avoid the effects of wind, wave and shadows caused by strong light, the low-altitude and breezy cloudy days were selected during the operation. The flying altitude, the heading overlap and the side overlap were about $460 \mathrm{~m}, 70 \%$, and 65\%, respectively, and the total of 2802 valid photos were 
obtained in the measurement. Besides, CORS (Continuous Operating Reference Stations) was used for the ground control point measurement and UAV navigation. To make the control points evenly distributed, the control points were chosen to be located along the middle of the survey area (Figure 3). There are no obvious markers as control points in the two study areas. So, we used the right-angle white cloth as the image control points.

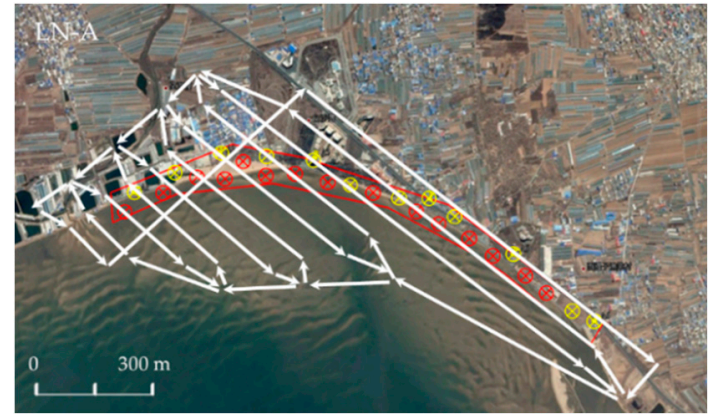

(a)

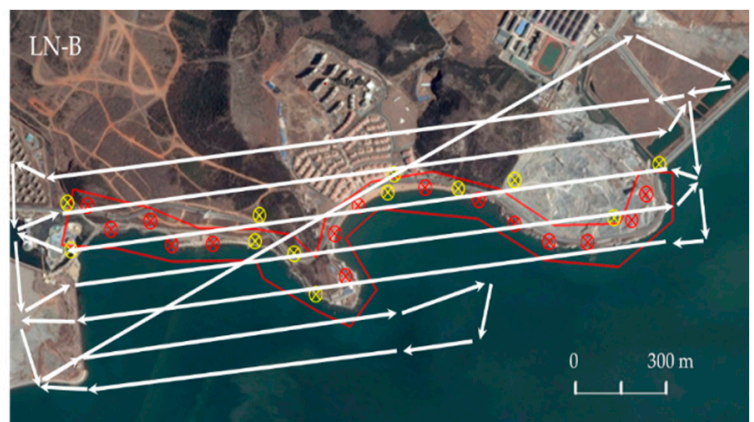

(b)

Figure 3. Flight routes and layouts of control points in the two study areas. The white lines represent the flight routes, the red polygons represent the shooting image coverage areas, 12 yellow dots represent orientation points for the subsequent net adjustment, and 15 red dots represent checkpoints for the subsequent accuracy evaluation. (a) Flying routes and layout of control points in LN-A. (b) Flying routes and layout of control points in LN-B.

\subsubsection{Data Collection of Tidal Level}

Three tidal gauges (Figure 4), A, B, and C, were selected to obtain long-term tidal level data for the calculation of local MHWS. Tidal gauge A locates near LN-A, tidal gauge B locates near LN-B and tidal gauge $\mathrm{C}$ distributes in the middle of LN-A and LN-B.

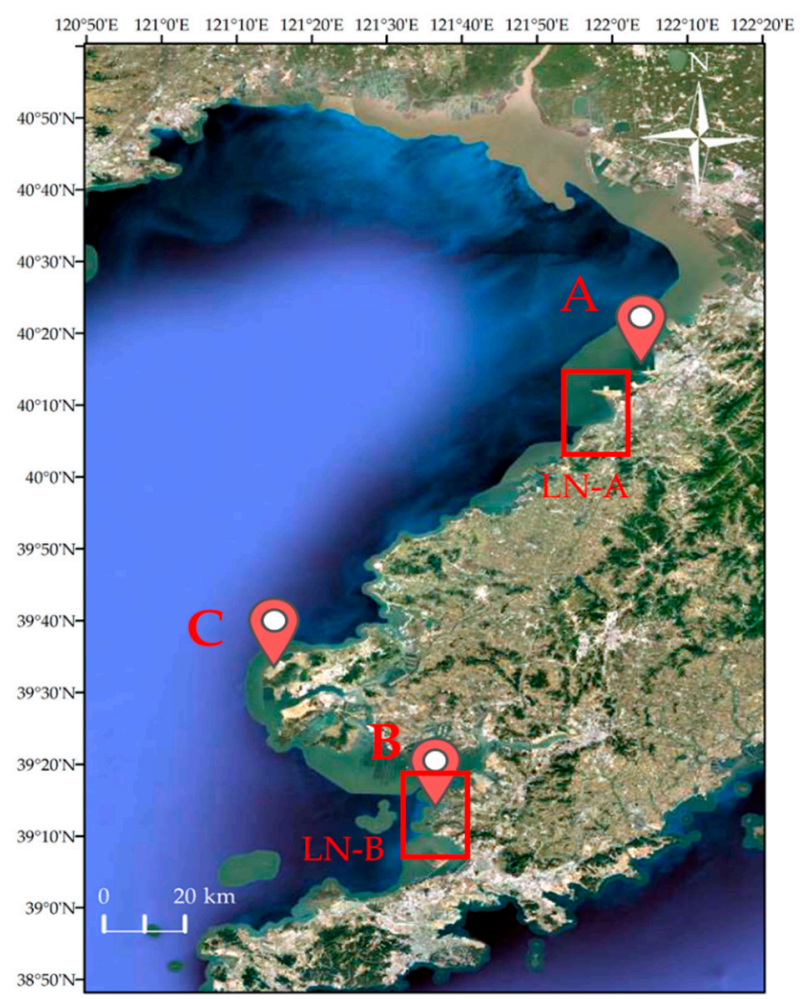

Figure 4. The distributions of the three tidal gauges and the study areas. A, B, and C represent three tidal gauges, and the red boxes are LN-A and LN-B. 
The on-the-fly GNSS tidal measurement facilitates the acquisition of instantaneous tidal levels at the ship's location in a short term. The GNSS tidal measurement was carried out by an unmanned boat equipped with a real time kinematic global navigation satellite system (GNSS-RTK) receiver, attitude sensor, and compass. In the meantime, using UAV tilt photogrammetry, the GNSS tidal measurement was synchronously performed to get the real-time tide level.

\subsection{Determinations of MHWS and Instantaneous Water-Surface Line}

\subsubsection{Data Processing on Long-Term Tidal Level}

The long-term tidal level data has two purposes, calculating MHWS and predicting the instantaneous tidal level.

The determination of MHWS for defining coastline needs long-term tidal level data. Three ways can be used for determining MHWS. The first way, when the measuring area is within the effective control range of a long-term tide gauge station, the tide level data of the tide gauge station can be directly used for the determination. MHWS can be obtained by directly calculating the mean value of tidal level data, or indirectly by tidal harmonic analysis method to calculate the tidal model of this sea area, from which the average sea surface height can be obtained. The second way, if the measuring area is beyond the control range of the long-term tide gauge station, the tide level series of several nearby long-term tide gauge stations can be used by taking into account the characteristics of tidal changes, and adopting a certain tidal interpolation model to interpolate the tide level series of the measured sea area. The tidal parameters (harmonic constants) can also be obtained through tidal harmonic analysis using the time series observation of long-term tide station heads. Using the tidal parameters of the several tidal stations, the tidal harmonic constants of each component are also interpolated to obtain the tidal height model for measuring any point in the waters. Then, the tidal level at different times in the waters is predicted and measured by the model, and the average high tide surface is calculated. The third way, when the tidal station is far away, the global tidal ocean model (GTOM) can be used to predict the tidal level. Up to now, GTOM has adopted different methods and data, resulting in different global and local accuracy. GTOM based on satellite altimeter data, such as TOPEX/Poseidon $(\mathrm{T} / \mathrm{P})$, are generally more accurate in open ocean areas, and there is little difference between the models, but these models in the shallow sea area have relatively large errors. GTOM can be roughly divided into empirical models and assimilation models. Among them, empirical models are based on satellite altimetry data, using empirical methods, such as tidal analysis, to obtain GTOM, such as CSR4.0 model. The assimilation model is based on the fluid dynamics equation, the models obtained by the assimilation of tidal measured data, such as the NAO. 99b and the TPXO 7.2, and are mostly based on national observation data and have high regional accuracy. If there is a considerable number of tidal station data near the survey area to participate in assimilation, the local tidal level is predicted with reference to the local regional model. For example, the NAO.99b model produced by the Japanese Observatory in China's offshore and Japanese waters is more accurate.

In this experiment, the first method was adopted to process the data because the study area was located directly within the effective control range of the long-term tide station. After obtaining the tidal observation data, the abnormal tide level needs to be eliminated, and the system deviation can be removed. The filtered tidal level data was used to calculate the mean high water springs $A_{M H W S}$. And then applied tidal harmonic analysis method to analyze the tidal data of long-term tidal stations near the experimental sea area for one year, and the least square method was chosen to establish the tidal model [40]. After getting $M H W S$, the sea surface model was included to convert $A_{M H W S}$ to the national elevation benchmark $H_{M H W S}$, namely the coastline elevation [41]

$$
H_{M H W S}=\zeta+A_{M H W S}
$$

where $\zeta$ is the height of the sea surface terrain expressed in the national elevation benchmark. 


\subsubsection{Data Processing on GNSS Tidal Level}

The data processing for obtaining instantaneous tide level includes GNSS elevation data filtering, ship attitude correction, draft correction, datum conversion, etc. Elevation data filtering is implemented by integrating Kalman filtering [42] and Heave correction technology [43]. Attitude correction is used to remove the effects of roll $(r)$, pitch $(p)$, and heave caused by wind and waves. Attitude correction is carried out in a hull coordinate system.

If the center coordinate of GNSS antenna is $\left(x_{0}, y_{0}, z_{0}\right)$, it changes to $(x, y, z)$ under the influence of ship attitude, and ignores the influence of the heading deviation (which does not affect $z$ value), then the actual coordinate $[x, y, z]^{T}$ is

$$
\left[\begin{array}{l}
x \\
y \\
z
\end{array}\right]=R_{r} R_{p}\left[\begin{array}{l}
x_{0} \\
y_{0} \\
z_{0}
\end{array}\right]=\left[\begin{array}{ccc}
1 & 0 & 0 \\
0 & \cos r & \sin r \\
0 & -\sin r & \cos r
\end{array}\right] \cdot\left[\begin{array}{ccc}
1 & 0 & 0 \\
0 & \cos p & \sin p \\
0 & -\sin p & \cos p
\end{array}\right] \cdot\left[\begin{array}{l}
x_{0} \\
y_{0} \\
z_{0}
\end{array}\right]
$$

The instantaneous elevation of the water surface $H_{W}$ is

$$
H_{w}=H_{G P S}-z
$$

where $H_{G P S}$ is the instantaneous height of the GNSS antenna center, and $z$ is the height from the antenna center to the hull center. It is also necessary to subtract the height from the hull center to the water surface (draft correction) and convert the height to the elevation system (datum conversion) where the tilt photogrammetry is located.

\subsubsection{Acquisition of Instantaneous Water Surface Line}

To determine the instantaneous water surface line, the instantaneous high precision tidal level is needed. The comprehensive tidal level model and GNSS tidal level should be considered, and the residual water level correction method should be adopted. The process is depicted as follows:

1. Calculate the tidal level according to the tidal level model from the tidal station data or GTOM.

2. Measure high-precision GNSS tidal level at GNSS anchor location.

3. Calculate the residual of the forecast tidal level by the tidal model through comparing with GNSS tidal level and construct a residual water level correction model in the area composed of several GNSS tide levels.

4. Correct the forecast water level to obtain the high-precision tidal level for determining instantaneous water surface line from the DEM of the coast zone.

\subsection{DEM Obtained by UAV Tilt Photogrammetry in Poor-Characteristic Coastal Zone}

\subsubsection{Traditional GNSS-Assisted Aerial Triangulation}

The process and principle of field operation and data processing for UAV tilt photography in the coastal zone are similar to those of land surveying [44,45]. Field flight operations include task formulation, airspace application, airline design, flight operations, inspection data, image preprocessing, and so on. The in-house data processing relies mainly on software, which includes image matching, aerial triangulation, dense matching, building triangulation, texture mapping, and generating 3D results. Among them, the accuracy of the coastal DEM is greatly affected by aerial triangulation, and the accuracy of aerial triangulation is often used as one of the indexes to evaluate the accuracy of DEM. It is difficult to get the DEM of the coastal zone due to poor characteristic, difficultly setting control points and large area covered by water. Therefore, a GNSS tidal level-assisted and waterline-constraint aerial triangulation method is proposed and detailed in the next section.

The traditional method of aerial triangulation in photogrammetry is to measure more than three ground control points in the field, then calculate the exterior azimuth elements by collinear equation, 
and then solve the coordinates of unknown points by forward intersection method, which is used for model orientation and subsequent mapping products generation. At present, most tilt photography software, such as Bentley's ContextCapture (Exton, PA, USA) and AgiSoft's PhotoScan (Agisoft LLC, St., Petersburg, Russia), use the bundle block joint adjustment method in the aerial triangulation step. The basic flow of aerial triangulation is as follows (Figure 5):

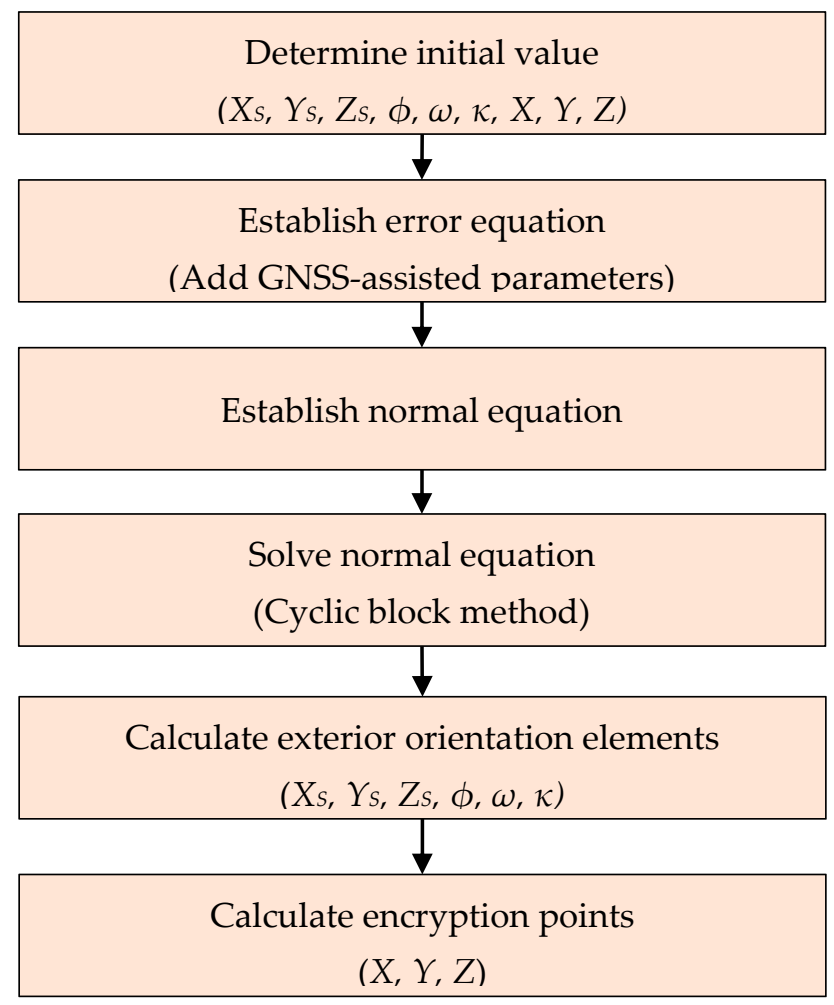

Figure 5. Flowchart of data processing of traditional Global Navigation Satellite System (GNSS)-assisted aerial triangulation.

1. Determining the approximate initial value of the exterior orientation elements of all images and the ground coordinates of the encrypted points.

2. Establishing the error equation about the encryption point and the control point of each image according to the collinear condition.

3. Establishing the normal equation of error equation point by point.

4. Using the elimination and cyclic block method to solve the normal equation.

5. Finding out the exterior orientation elements of each image.

6. Calculating encryption points by forward intersection.

Due to various systematic errors in the aerial survey process, some additional parameters are often selected to form a system error model to improve the accuracy of block adjustment results. These additional parameters are taken as unknown or weighted observations and are solved together with other unknown parameters of regional network to calibrate and eliminate the influence of systematic errors in the adjustment process, which is called self-calibration bundle block adjustment. The mathematical model is based on the collinear conditional equation and considering the system errors of the image points. It can be expressed as

$$
\begin{aligned}
x-x_{0}+\Delta x & =-f \frac{a_{1}\left(X-X_{s}\right)+b_{1}\left(Y-Y_{s}\right)+c_{1}\left(Z-Z_{s}\right)}{a_{3}\left(X-X_{s}\right)+b_{3}\left(Y-Y_{s}\right)+c_{3}\left(Z-Z_{s}\right)} \\
y-y_{0}+\Delta y & =-f \frac{a_{2}\left(X-X_{s}\right)+b_{2}\left(Y-Y_{s}\right)+c_{2}\left(Z-Z_{s}\right)}{a_{3}\left(X-X_{s}\right)+b_{3}\left(Y-Y_{s}\right)+c_{3}\left(Z-Z_{s}\right)}
\end{aligned}
$$


where $x-x_{0}, y-y_{0}$ represent the image plane coordinates of the image point in the coordinate system with the image main point as the origin; $\Delta x, \Delta y$ are, respectively, described by a systematic error model with additional parameters; $f$ is the focal length; $X, Y$, and $Z$ represent the coordinates of the point corresponding to the encrypted points in the rectangular coordinate system of the object space; $X_{S}, Y_{S}$, and $Z_{S}$ are the coordinates of the projection center in the object coordinate system, that is, the exterior orientation elements of the image; $a_{1}, a_{2}, a_{3}, \ldots, c_{3}$ are the direction cosines represented by the image exterior azimuth elements $\phi, \omega, \kappa$; and the equation can be expanded to a linear term according to the Taylor series expansion:

$$
\begin{aligned}
& V_{X}=A t+B x+C c-L_{X}, \text { weight } E \\
& V_{S}=E_{C} C-L_{S} \text {, weight } P_{S} \\
& V_{I}=E_{I} i-L_{I} \text {, weight } P_{I} \text {, } \\
& A=\left[\begin{array}{llllll}
a_{11} & a_{12} & a_{13} & a_{14} & a_{15} & a_{16} \\
a_{21} & a_{22} & a_{23} & a_{24} & a_{25} & a_{26}
\end{array}\right], B=\left[\begin{array}{lll}
-a_{14} & -a_{15} & -a_{16} \\
-a_{24} & -a_{25} & -a_{26}
\end{array}\right] \\
& t=\left[\begin{array}{llllll}
\Delta X_{S} & \Delta Y_{S} & \Delta Z_{S} & \Delta \varphi & \Delta \omega & \Delta \mathcal{K}
\end{array}\right] \\
& x=\left[\begin{array}{lll}
\Delta X & \Delta Y & \Delta Z
\end{array}\right]^{T},
\end{aligned}
$$

where $V_{X}, V_{S}$, and $V_{I}$ are the correction vector value of the encryption point coordinates (including control points), the virtual self-calibration parameters, and the interior orientation parameters in the image; $L_{X}, L_{S}$, and $L_{I}$ are absolute terms; $i=\left[\Delta x_{0} \Delta y_{0} \Delta f\right]^{T}$ is the unknown vector of interior orientation parameters; $c=\left[\begin{array}{lll}a_{1} & a_{2} & a_{3}\end{array}\right]^{T}$ is vector of self-calibration parameters, and $C$ is the coefficient matrix corresponding to the $c$, which varies with the error correction model of the selected image point coordinate system.

In the coastal environment where the control points are uneven and insufficient, the GNSS coordinates of the instantaneous photography center are jointly added to the adjustment, especially in areas without control points, such as waters, cliffs, and tidal flats. In field surveying, GNSS surveys acquire the coordinates of the phase center of the receiver antenna rather than those of the photographic center due to the eccentric vector between them. The aerial camera is fixed on the aircraft, the eccentricity vector is a constant, which is expressed as $(u, v, w)$ in the image square coordinate system. According to the study by Friess et al. [46], dynamic GNSS positioning based on carrier-phase measuring will produce a systematic error (drift system error) that varies linearly with the aerial time $t$ in aerial photography (generally no more than $15 \mathrm{~min}$ ); $t_{0}$ is the reference time, $a_{X}, a_{Y}, a_{Z}, b_{X}, b_{Y}, b_{Z}$ is the correction error parameter of the GNSS drift system error, and $\left(X_{A}, Y_{A}, Z_{A}\right)$ denotes the coordinate that removes the eccentric vector. The established geometric relationship is:

$$
\left[\begin{array}{l}
X_{A} \\
Y_{A} \\
Z_{A}
\end{array}\right]=\left[\begin{array}{c}
X_{S} \\
Y_{S} \\
Z_{S}
\end{array}\right]+R \cdot\left[\begin{array}{c}
u \\
v \\
w
\end{array}\right]+\left[\begin{array}{c}
a_{X} \\
a_{Y} \\
a_{Z}
\end{array}\right]+\left(t-t_{0}\right) \cdot\left[\begin{array}{c}
b_{X} \\
b_{Y} \\
b_{Z}
\end{array}\right]
$$

The error equation can be written as:

$$
V_{G}=\bar{A} t+R r+D d-L_{G}
$$




$$
\begin{aligned}
& V_{G}=\left[\begin{array}{c}
v_{X_{A}} \\
v_{Y_{A}} \\
v_{Z_{A}}
\end{array}\right],\left[\begin{array}{c}
U \\
V \\
W
\end{array}\right]=\left[\begin{array}{c}
X_{A}-X_{S} \\
Y_{A}-Y_{S} \\
Z_{A}-Z_{S}
\end{array}\right]=R \cdot\left[\begin{array}{c}
u \\
v \\
w
\end{array}\right], L_{G}=\left[\begin{array}{c}
X_{A} \\
Y_{A} \\
Z_{A}
\end{array}\right]-\left[\begin{array}{c}
X_{A} \\
Y_{A} \\
Z_{A}
\end{array}\right]^{0} \\
& \bar{A}=\left[\begin{array}{ll}
A & E
\end{array}\right]=\left[\begin{array}{cccccc}
-W & -V \sin \varphi & -c_{3} V+b_{3} W & 1 & 0 & 0 \\
0 & U \sin \varphi-W \cos \varphi & -a_{3} W+c_{3} U & 0 & 1 & 0 \\
U & V \cos \varphi & -b_{3} U+a_{3} V & 0 & 0 & 1
\end{array}\right] \\
& D=\left[\begin{array}{cccccc}
1 & 0 & 0 & t-t_{0} & 0 & 0 \\
0 & 1 & 0 & 0 & t-t_{0} & 0 \\
0 & 0 & 1 & 0 & 0 & t-t_{0}
\end{array}\right] \\
& t=\left[\begin{array}{llllll}
\Delta X_{S} & \Delta Y_{S} & \Delta Z_{S} & \Delta \varphi & \Delta \omega & \Delta \mathcal{K}
\end{array}\right] \\
& d=\left[\begin{array}{llllll}
a_{X} & a_{Y} & a_{Z} & b_{X} & b_{Y} & b_{Z}
\end{array}\right]^{T},
\end{aligned}
$$

where $R$ is the coefficient matrix corresponding to $r$. It is an orthogonal transformation matrix composed of the attitude angle of the image.

\subsubsection{Improved Waterline-Constraint Aerial Triangulation}

The accuracy of DEM obtained by the above traditional tilt photography of UAV in the coastal zone is often not high in the coastal zone with poor characteristics. The following factors cause the shortcoming.

1. It is difficult to set control points on these areas, such as the sea surface, the reefs, the tidal flats, etc. A small amount of control points unevenly distributes in the coastal zone, which will increase the matching difficulty and lead to the accuracy of DEM decreasing.

2. The narrow geographical environment of the coastal zone also causes great troubles for route design and control point layout, which affects the accuracy of aerial triangulation, especially vertical accuracy.

3. The images in the coastal zone include flooded large areas, and the image features are barren in these areas.

It is found that the coordinates of the projection center determined by GNSS can be used as auxiliary data for the block joint adjustment, which is called GNSS-assisted block joint adjustment, to induce the requirement of aerial control points. It is very suitable for the coastal zone environment of uncontrolled areas and narrow terrain. Besides, due to the short time interval between the two photographs used for forming stereo image pair, it can be assumed that the water boundary of the coastal zone corresponding to the two photographs has not changed significantly. It is easy to find the corresponding image points of the water boundary on the left and right images, and we can consider that the elevations of those points on the water boundary equal in the adjacent images. Therefore, these water-boundary points can be introduced as contour control points in the adjustment process for improving the location accuracy of the coastal elevation. The elevations of these contour points can be obtained by GNSS tide level measurement.

In view of the above factors, and taking full account of the characteristics of poor coastal control points and numerous water surfaces, this paper proposes a GNSS-assisted aerial triangulation method with contour constraints of water boundary and GNSS in tide level measurement: during the field flight of UAV, GNSS in tide level measurement is carried out to calculate the water surface elevation at the moment of photographing under the same datum; in the process of aerial triangulation, a series of suitable points along the gentle water boundary are selected as the contour control points and are used in the bundle block adjustment with GPS data and control point data to jointly calculate the ground coordinates of the encryption points.

It should be noted that the instantaneous water surface height will be disturbed by wind, tide, and other factors. It is necessary to ensure that the water surface height is only affected by tide when the UAV measuring system is shooting and works in low tide and windless environment. When 
choosing several points as contour points on the local waterfront, we should avoid human disturbance, such as ships, and choose a smooth and wave-free waterfront.

The image points' coordinates of contour points are obtained by space forward intersection, and their corresponding coordinates of ground points are unknown, but the elevation values of ground coordinates (set as $\mathrm{Ze}$ ) are equal for the same set of contour points. Therefore, when adding $n(n \geq 2)$ contour points, $n$ equations related to the elevation values of ground coordinates can be listed, and the elevation value only adds an unknown value $Z e$. Then, the bundle block adjustment error equation can be depicted as follows:

$$
V_{X}=A t+B x-L_{X}
$$

When the number of encryption points reaches $n 1$, we have

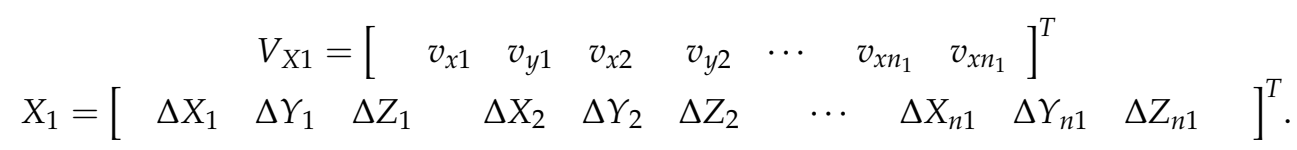

When the number of control points reaches $n 2$, we have

$$
\begin{aligned}
& V_{X 2}=\left[\begin{array}{lllllll}
v_{x 1} & v_{y 1} & v_{x 2} & v_{y 2} & \cdots & v_{x n_{2}} & v_{x n_{2}}
\end{array}\right]^{T} \\
& X_{2}=\left[\begin{array}{cccccccccc}
\Delta X_{1} & \Delta Y_{1} & \Delta Z_{1} & \Delta X_{2} & \Delta Y_{2} & \Delta Z_{2} & \cdots & \Delta X_{n 2} & \Delta Y_{n 2} & \Delta Z_{n 2}
\end{array}\right]^{T} \\
& \Delta X_{1}=\Delta Y_{1}=\Delta Z_{1}=\Delta X_{2}=\Delta Y_{2}=\Delta Z_{2}=\cdots=\Delta X_{n 2}=\Delta Y_{n 2}=\Delta Z_{n 2}=0 .
\end{aligned}
$$

When the number of constrained contour points of water boundary contour reaches $n 3$,

$$
\begin{gathered}
V_{X 3}=\left[\begin{array}{llllllllll} 
& v_{x 1} & v_{y 1} & v_{x 2} & v_{y 2} & \cdots & v_{x n_{3}} & v_{x n_{3}}
\end{array}\right]^{T} \\
X_{3}=\left[\begin{array}{ccccccccccc}
\Delta X_{1} & \Delta Y_{1} & \Delta Z_{e} & \Delta X_{2} & \Delta Y_{2} & \Delta Z_{e} & \cdots & \Delta X_{n 3} & \Delta Y_{n 3} & \Delta Z_{e}
\end{array}\right]^{T} .
\end{gathered}
$$

$Z e^{\prime}$ s initial value is obtained from the instantaneous water surface elevation calculated by on-the-fly GNSS tidal measurement. When the accuracy is up to the requirement, its initial value can be set to 0 . The plane coordinates of the control points of the waterline are the same as those of the encrypted points, which are set as unknown numbers.

In summary, the error equation of GNSS-assisted and self-calibration bundle block adjustment with contour constraints is as follows:

$$
\begin{aligned}
& V_{X 1}=A t+B x_{1}+C c-L_{X}, \text { weight } E_{1} \\
& V_{X 2}=A t+B x_{2}+C c-L_{X}, \text { weight } E_{2} \\
& V_{X 3}=A t+B x_{3}+C c-L_{X}, \text { weight } E_{3} \\
& V_{S}=E_{C} c-L_{S}, \text { weight } P_{S} \\
& V_{G}=\bar{A} t+R r+D d-L_{G}, \text { weight } P_{G},
\end{aligned}
$$

where the interior orientation parameters $(x, y, f)$ of those images are regarded as the known value. $V_{X 1}, V_{X 2}, V_{X 3}, V_{S}$, and $V_{G}$ represents the coordinates correction vector value of the encryption points, the ground control points, the constrained contour points, the virtual self-calibration parameters, and the GNSS photography center points, respectively.

In the process of least squares adjustment, when the distribution of horizontal and vertical control points is relatively uniform and the control for sea and land is more ideal, the weight of control points of water boundary can be assigned smaller.

\subsubsection{Tilt Photography Data Processing}

The UAV tilt photography data includes a set of orthophoto data set, 4 tilt image sets, corresponding POS data and control point coordinate data. After manually deleting the testing images and poor-quality ones, the image data should be named standardly and ensure the same shooting time. POS data 
is post processed by Applanix's POSPac software (Richmond Hill, Toronto, ON, Canada) matched with POS/AV system, and merged with Inertial Measurement Unit (IMU) data by Applanix IN-fusion technology. Setting the correct offset value and map projection in the software, we finally get the accurate exterior orientation elements of the image. In order to ensure the accuracy of the results, 27 ground control points are collected in areas A and B, 12 of which are used as encryption points to participate in adjustment, and the other 15 are used as check points to evaluate the accuracy. Finally, the software automatically generates dense 3D point cloud, high-precision DEM and 3D real scene model in the experimental area, and the RMS error of image control point is $\pm 8 \mathrm{~mm}$. The local precise geoid model is used to transform the vertical datum, and the results are unified under the national elevation datum. The specific processing flow is as follows (Figure 6):

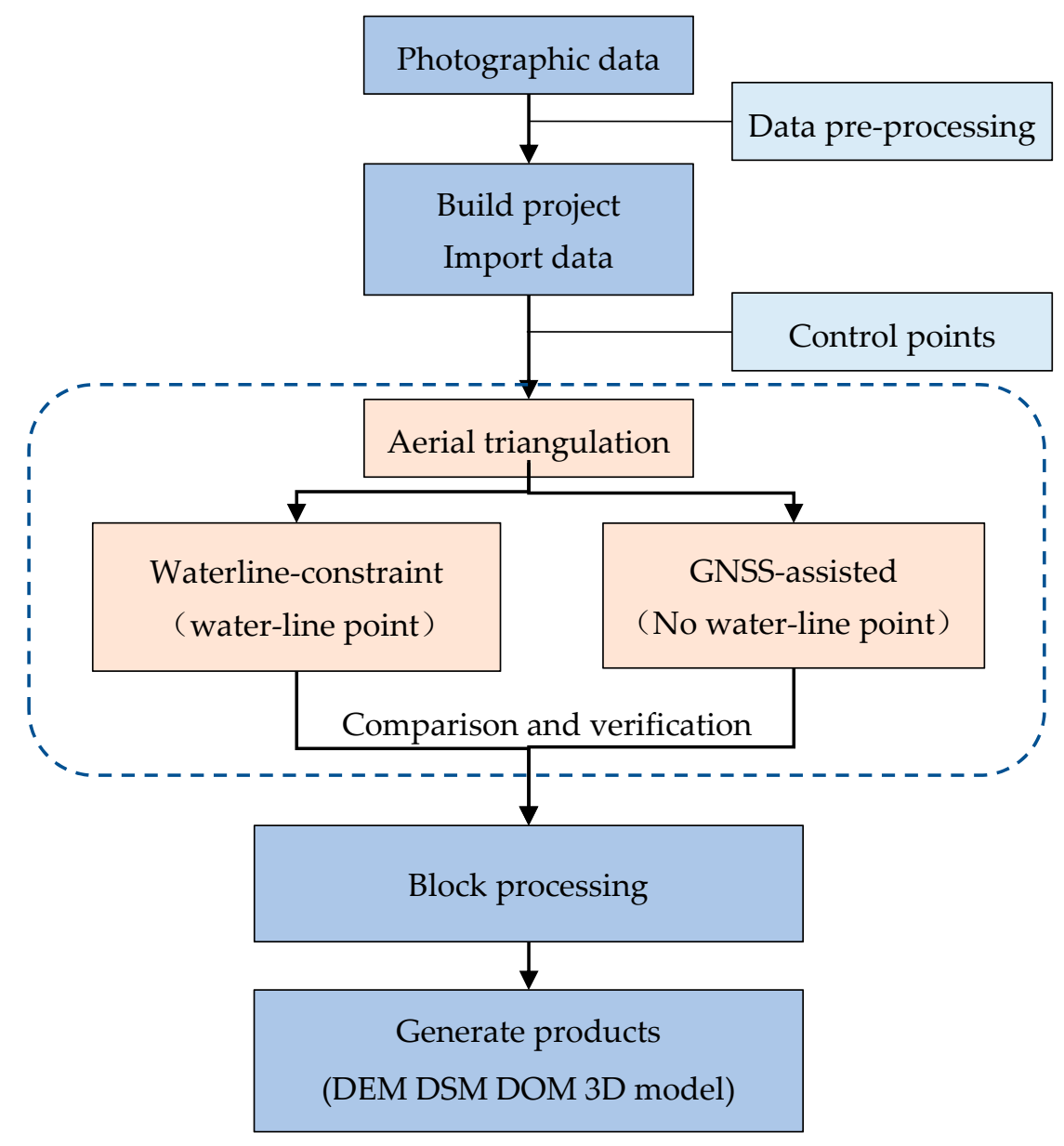

Figure 6. Flowchart of data processing for UAV tilt photogrammetry.

1. Data pre-processing: establish a new project, import image data, image control point coordinate file, and POS data.

2. Internal piercing control points: after field measurement of image control points, according to the photos of the measured image control points and the points selected on the spot, artificial pricking is carried out on the photos.

3. Aerial triangulation: set adjustment calculation mode and strategy, use the image external orientation element obtained by POS/AV system as the weighted observation value of regional network adjustment, and participate in joint adjustment together with the ground control point. All of those are set to equal weights and participate in the AT calculation together to get higher precision exterior orientation elements. Repeat (2) (3) until the adjustment accuracy meets the 
requirements. After the completion of AT, a calculation report and a new block are generated, and each image has accurate internal and external orientation elements.

4. Increase water-line contour points: several local water areas are selected near the experimental coast where is calm. Five to fifteen points are chosen for each water area as the contour constraint points. The elevation value is determined by the measurement of the tide level in flight, and the plane coordinate is set as the unknown value. Together with the control point and POS data, it is used as the equal weight observation value to participate in the aerial triangulation.

5. Block processing: after aerial triangulation, a block containing a large number of images is obtained. Computer memory and calculation time need to be taken into account to divide the block into several sub-blocks to participate in modeling.

6. Generate products: set the coordinate system and modeling area, and select the output form (DEM, DSM, DOM, 3D model). The output format is determined by the relevant attributes and production purposes of the reconstruction project.

\subsection{Determination of Coastline}

\subsubsection{Coastline Processing}

According to the mechanism of tidal motion, it can be considered that the amplitude and frequency of tidal changes in a small area are basically the same, which means that MHWS can be regarded as a contour in reality. The general idea is to obtain the coastal DEM and coastline elevation under the same vertical datum and determine the horizontal position of the coastline by using contour tracing technology (Figure 7).

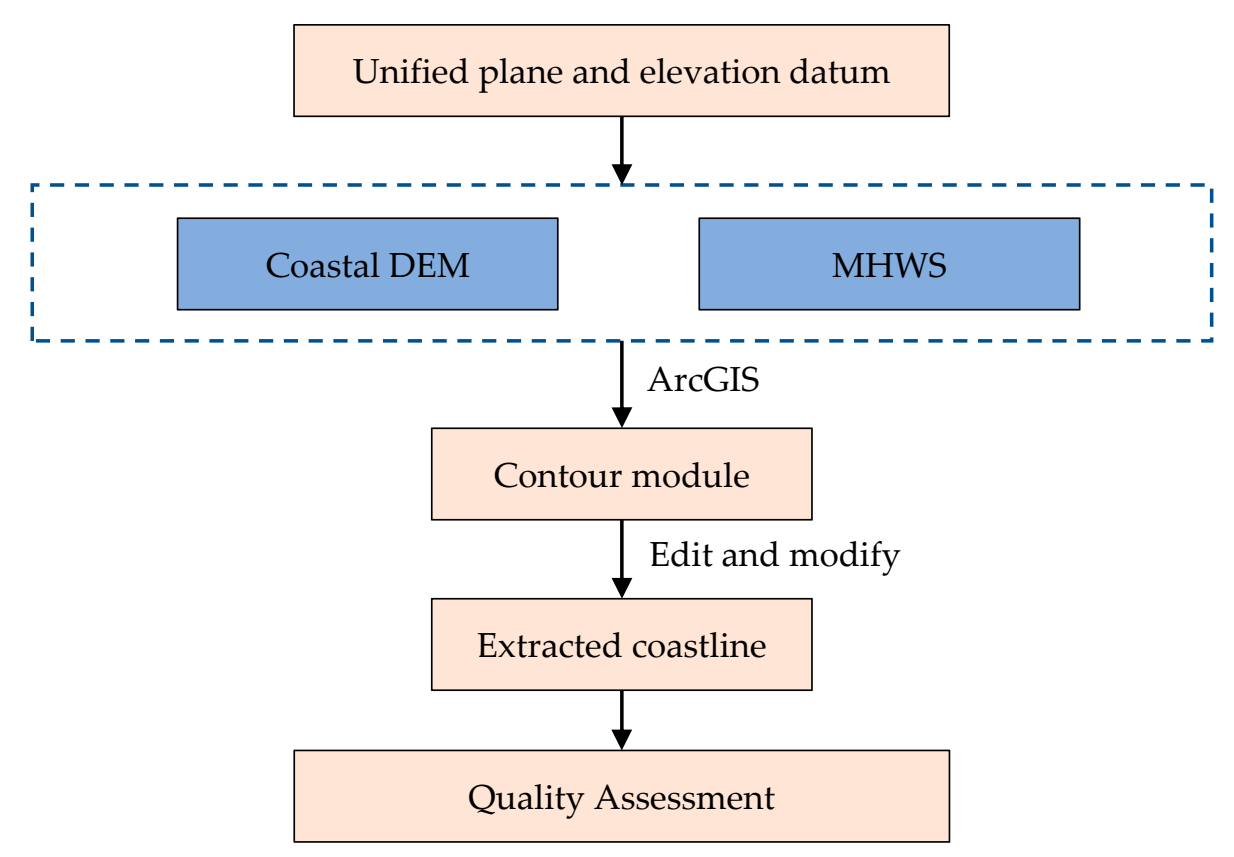

Figure 7. Flowchart of coastline determination.

The seeking coastline is completed by ArcGIS software. The coastal DEM are first input into ArcGIS software, and, then, the given contour is sought out by "Raster Surface" option of the "3D Analyst tools" (Figure 8). In the process, it needs to be noted that the input DEM is raster data, MHWS is set as basic contour, and the contour interval is set to be much higher than the MHWS to guarantee the single coastline to be obtained. Besides, the obtained coastline also needs to be smoothed and edited by using the editing vector line function. After the above process, the coordinates of the coastline points are obtained and marked in the map of the coastal zone. 


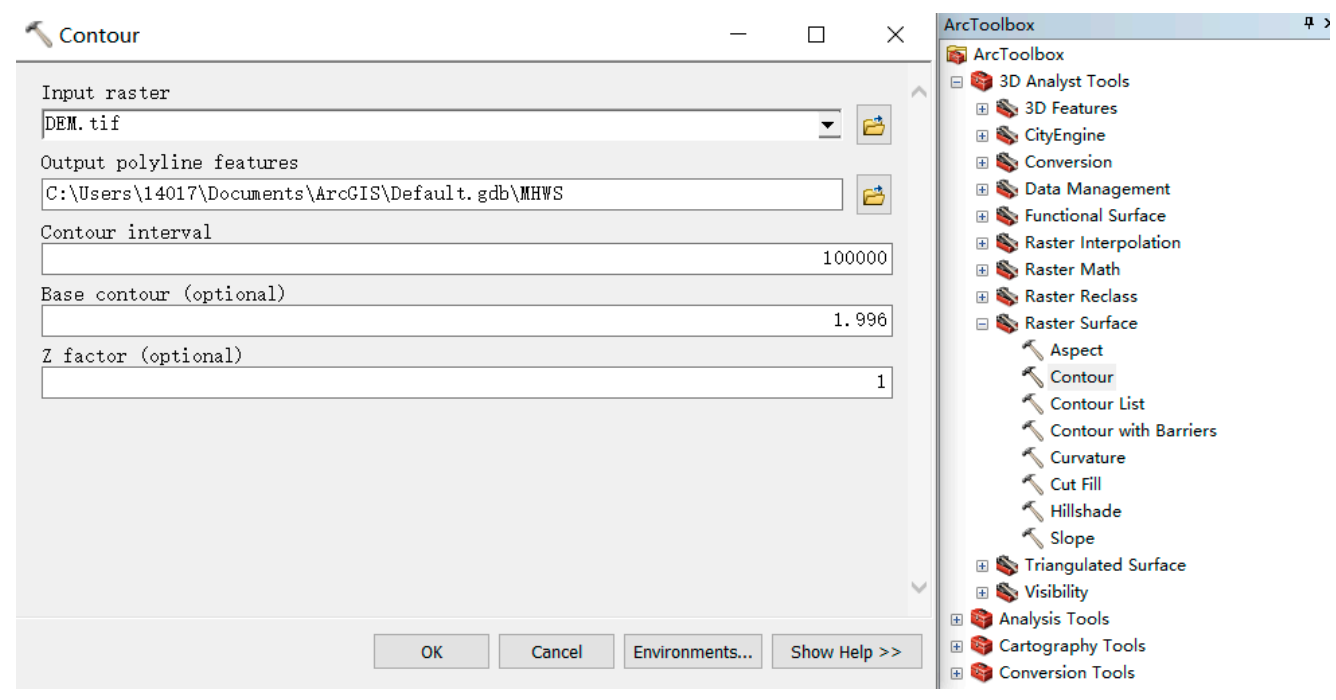

Figure 8. Parameter setting and coastline determination in ArcGIS software.

\subsubsection{Quality Assessment}

To evaluate the determined coastline, it is necessary to analyze the error and the accuracy of the extracted coastline.

MHWS is a value of theoretical shoreline, which cannot be directly surveyed and mapped. However, the trace line refers to the accumulation of rock at the tidal flat or the formation of sand due to seawater immersion, which is the only visible basis for field measurement. UAV tilt photography can produce high-resolution 3D real-world models, and based on the significant color difference features, the trace lines in the model could be extracted and then used as the basis for assessing the accuracy of the coastline position. The evaluation is carried out in both qualitative and quantitative aspects. The qualitative analysis is to superimpose the extracted coastline onto the DOM and subjectively evaluate the extraction manually. The quantitative analysis is to compare the extracted shoreline and the trace line with the plane and elevation coordinates.

The specific method is to sample every other distance along the extracted coastline and determine the corresponding points of the trace lines in the gradient direction of the coastline [47], calculating the vertical difference $\Delta H$ and plane position deviation $\Delta V$ of the corresponding point pair, respectively, as well as the mean, root mean square deviation, and standard deviation indexes of those difference.

$$
\begin{aligned}
& \Delta H=Z_{\text {trace }}-Z_{M H W S} \\
& \Delta V=\sqrt{\left(X_{\text {trace }}-X_{M H W S}\right)^{2}+\left(Y_{\text {trace }}-Y_{M H W S}\right)^{2}} \\
& \operatorname{Mean}_{\Delta}=\frac{\sum \Delta_{i}}{n} \\
& \operatorname{RMS}_{\Delta}=\sqrt{\frac{\sum \Delta_{i}^{2}}{n}} \\
& S T D_{\Delta}=\sqrt{\frac{\sum\left(\Delta_{i}-\text { Mean }_{\Delta}\right)^{2}}{n-1} .} .
\end{aligned}
$$

\section{Results and Evaluation}

\subsection{Results of Tidal Harmonic Analysis}

The tidal harmonic analysis method is used to analyze the tidal data of long-term tidal stations near the experimental sea area for one year, and the least square method is chosen to establish the tidal model. It can be seen from the residual diagram (Figure 9):

1. The deviation of the tide height model changes within $-20 \mathrm{~cm} \sim 20 \mathrm{~cm}$. 
2. The calculated water level and the measured water level based on the tide height model have good consistency in phase and amplitude.

3. At high and low tide levels, the accuracy of the high tide model is relatively reduced.

4. Counting the calculation deviation of the tide level model of the three tide level stations, the mean square errors of the calculation results of the three stations are $10.1 \mathrm{~cm}, 12.4 \mathrm{~cm}$, and $10.3 \mathrm{~cm}$, respectively.

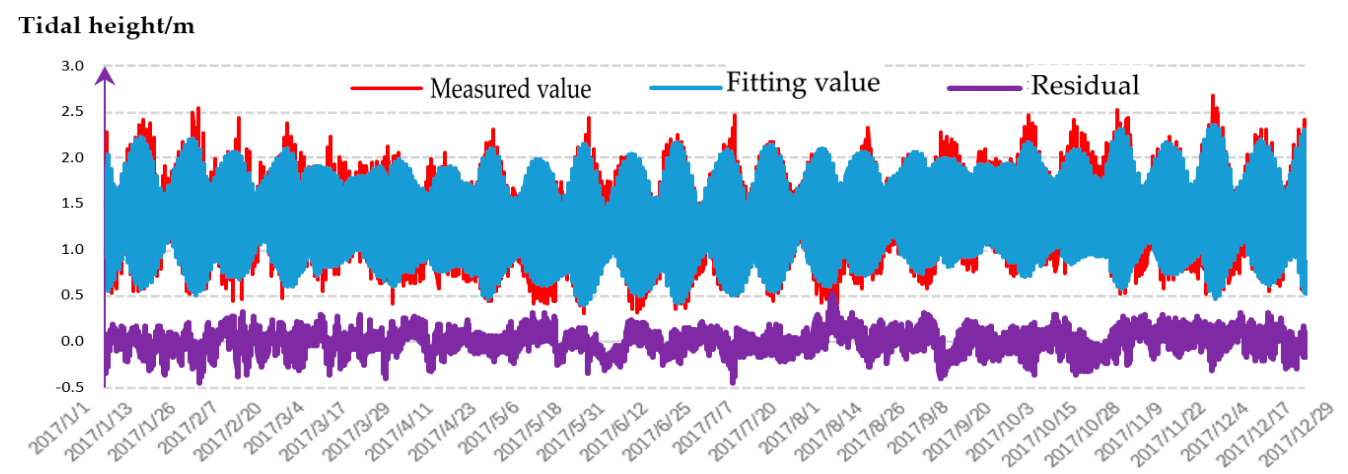

(a)

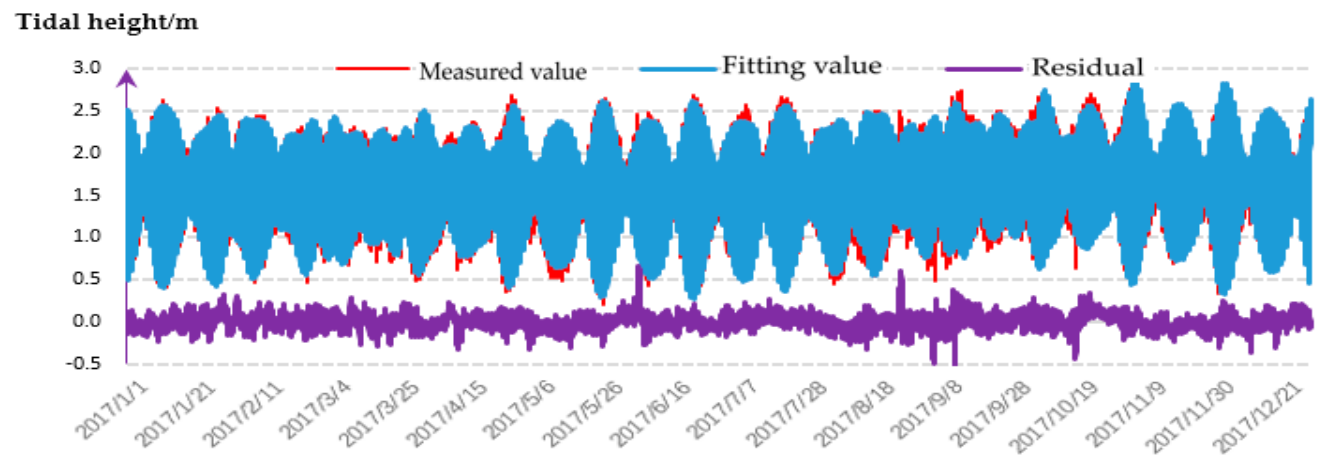

(b)

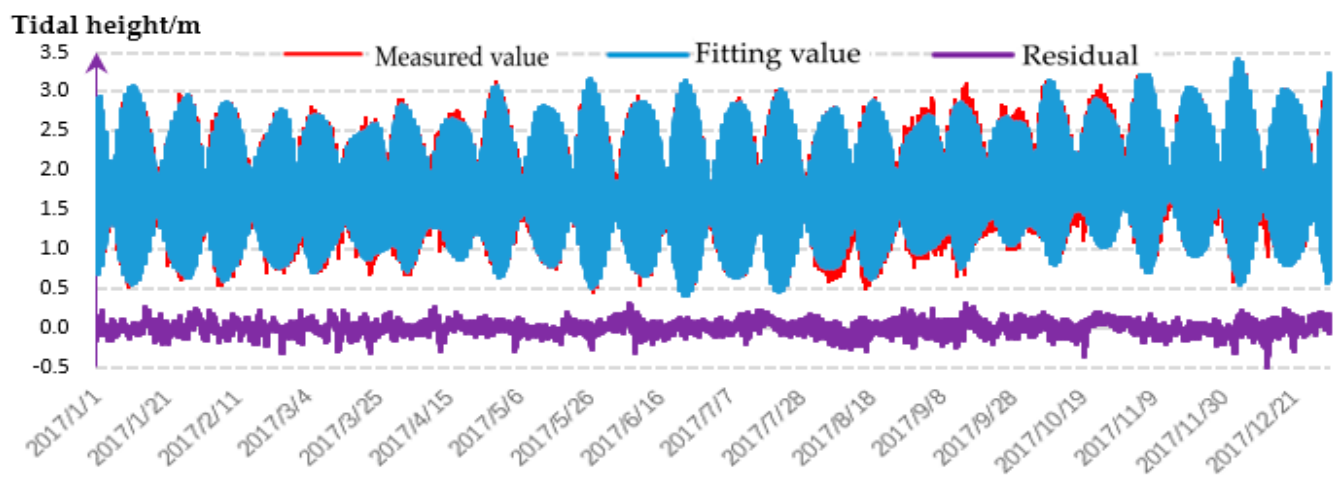

(c)

Figure 9. Measured tidal level, the forecast one and the deviations of the forecast tidal level. Those in tidal gauge $\mathrm{A}(\mathbf{a}), \mathrm{B}(\mathbf{b})$, and $\mathrm{C}(\mathbf{c})$.

With the help of the 13-tide tidal model of three tidal stations, the 1-month and 3-month tidal forecasts were carried out. The prediction accuracy distribution of the 1 tide station was $9.7 \mathrm{~cm}$ and 
$11.1 \mathrm{~cm}$, the 2 tide station was $13.6 \mathrm{~cm}$ and $14.2 \mathrm{~cm}$, and the 3 tide station was $10.3 \mathrm{~cm}$ and $11.4 \mathrm{~cm}$, which is a good result in ocean tide data processing.

\subsection{Results of MHWS and Instanteous Waterline Height}

According to the distribution of the three long-term tidal stations in the coastal zone and the characteristics of tidal variation, the MHWS at different locations (LN-A and LN-B) along the coastal zone is obtained by using the method of tidal level interpolation, and then the MHWS curve along the coastal zone is formed. Combining the local average sea level model with the GNSS joint measurement results at each tidal level station, the above tidal characteristic parameters and aerial triangulation survey results are unified to a same vertical datum. Based on these, the MHWSs of the two regions are obtained. And the real-time tide level of LN-A and LN-B are calculated by the results of GNSS in-flight tide level measurement and tide model prediction, in which the relationship with MHWS under the mean sea level datum are shown in Figure 10.

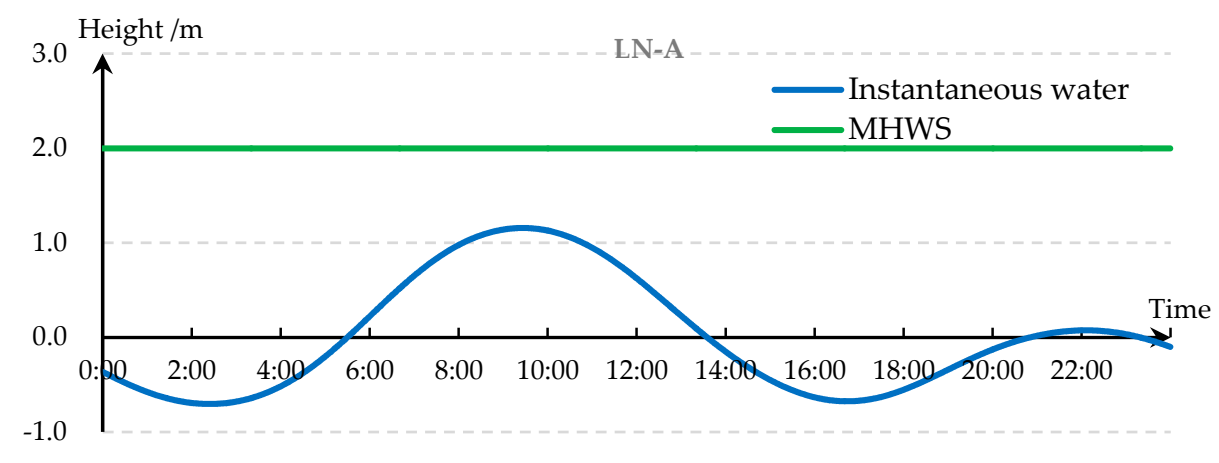

(a)

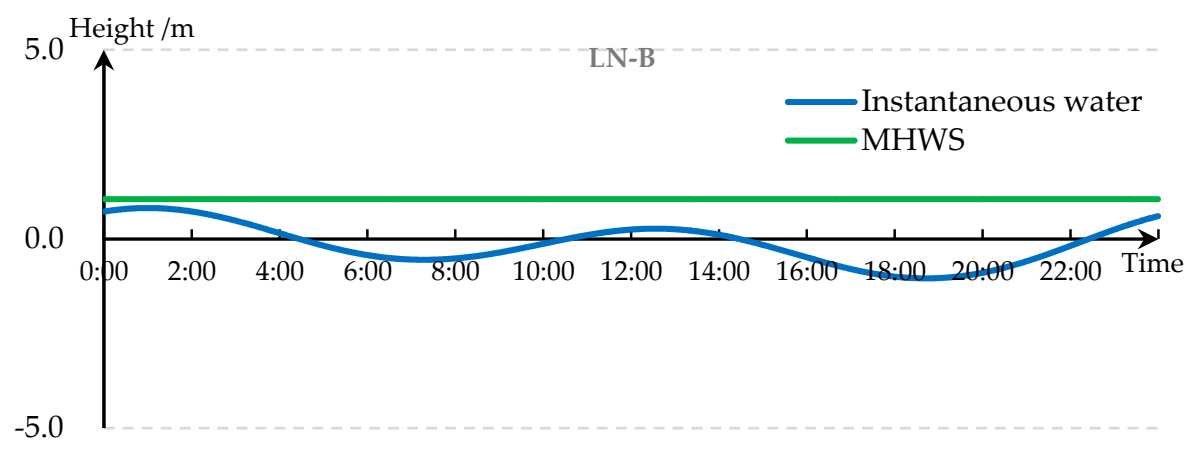

(b)

Figure 10. Instantaneous waters and HMWS in LN-A (a) and LN-B (b).

\subsection{Results of Tilt Photography}

The aerial triangulation experiment was performed in two groups. One was GNSS-assisted aerial triangulation without water edge constraint, 12 points were used as orientation points to participate in adjustment, and 15 points were used as checkpoints. The other was GNSS-assisted aerial with additional water edge constraint for triangulation, 12 points are also used as adjustment points for adjustment, and 15 points are used as checkpoints. The influence of increased water-line contour points or none on the accuracy of aerial triangulation is obtained through comparison. The final accuracy indicator of aerial triangulation is the RMSE and maximum residual in the plane (elevation) coordinates of the checkpoint. Table 1 shows the AT accuracy of the two measurements. 
Table 1. The accuracy statistic of bundle block adjustment.

\begin{tabular}{|c|c|c|c|c|c|c|c|c|c|c|}
\hline \multicolumn{3}{|c|}{ Test } & \multicolumn{4}{|c|}{$\begin{array}{c}\text { Maximum Residuals of } \\
\text { Check Point Coordinates (m) }\end{array}$} & \multicolumn{4}{|c|}{$\begin{array}{l}\text { Root Mean Square Deviation of } \\
\text { Check Point Coordinates (m) }\end{array}$} \\
\hline & & & East & North & Plan. & Height & East & North & Plan. & Height \\
\hline 1 & \multirow{2}{*}{$\begin{array}{l}\text { No water-line } \\
\text { point }\end{array}$} & LN-A & 0.09 & 0.10 & 0.11 & 0.13 & 0.08 & 0.07 & 0.11 & 0.10 \\
\hline 2 & & LN-B & 0.07 & 0.08 & 0.10 & 0.15 & 0.07 & 0.07 & 0.10 & 0.12 \\
\hline 3 & \multirow{2}{*}{ Water-line point } & LN-A & 0.09 & 0.08 & 0.12 & 0.08 & 0.07 & 0.07 & 0.10 & 0.06 \\
\hline 4 & & LN-B & 0.08 & 0.08 & 0.11 & 0.09 & 0.07 & 0.06 & 0.09 & 0.06 \\
\hline
\end{tabular}

For Test 1 and 3, the coordinate RMSE of all check points is better than $\pm 0.10 \mathrm{~m}$ in horizon and elevation, respectively, and the maximum coordinate bias are $0.12 \mathrm{~m}$ in horizon and $0.13 \mathrm{~m}$ in elevation. This result meets the accuracy requirement of the AT for the flat topography mapping at the scale of 1:2000, which requires that the tolerance of check point coordinate unconformities should be less than $0.25 \mathrm{~m}$ for planimetry and less than $0.30 \mathrm{~m}$ for elevation determination (GB 7930-87, 1998).

For Test 2 and 4, the coordinate RMSE of all check points is better than $\pm 0.11 \mathrm{~m}$ in planimetry and is better than $\pm 0.12 \mathrm{~m}$ in elevation, and the maximum coordinate unconformities are $0.11 \mathrm{~m}$ in planimetry and $0.15 \mathrm{~m}$ in elevation. This result also satisfies the accuracy requirement of the AT for the mountain topography mapping at the scale of 1:2000, which requires that the tolerance of check point coordinate unconformities should be less than $0.35 \mathrm{~m}$ for planimetry and less than $0.40 \mathrm{~m}$ for elevation determination (GB 7930-87, 1998).

Comparing 1, 2, or 3 and 4, the plane accuracy of the two areas A and B is not much different, but the vertical accuracy of the LN-A area is significantly better than that of the LN-B area. The area of LN-A has frequent human activities, and the terrain is relatively small. It is mainly composed of sandy beaches, artificial banks, and artificial breeding grounds, which should be regarded as flat land with obvious changes in the characteristics of the image. The area of LN-B has fewer human activities and larger topographic relief. The towering cliffs and low-lying beaches are scattered and make LN-B looks like hilly area. The terrain in the image is similar, which is not conducive to matching. In general, images with smaller terrain or flat and more feature changes have higher vertical accuracy in aerial triangulation.

Comparing test 1 with test 3 and 2 with 4, the RMSE and the maximum residual error in elevation of the additional waterline point AT are smaller than conventional aerial triangulation, but there is no significant difference with respect to the RMSE and the maximum residual error in horizon, which shows the traditional method will bring low-accuracy elevation when suffering poor-characteristic coastal zone, as well as verifies the proposed method with the assistant of waterline points.

Using the aerial triangulation results with additional waterline point to carry out regional segmentation, dense matching and modeling of feature points, and the final DEMs of the experimental areas are obtained (Figure 11). 


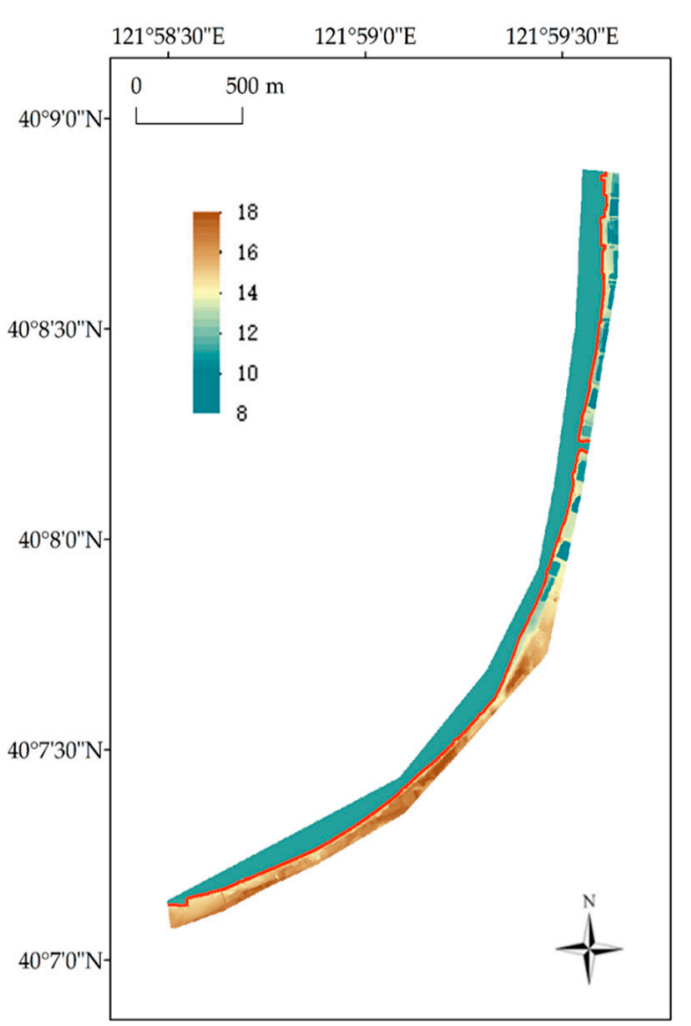

(a)

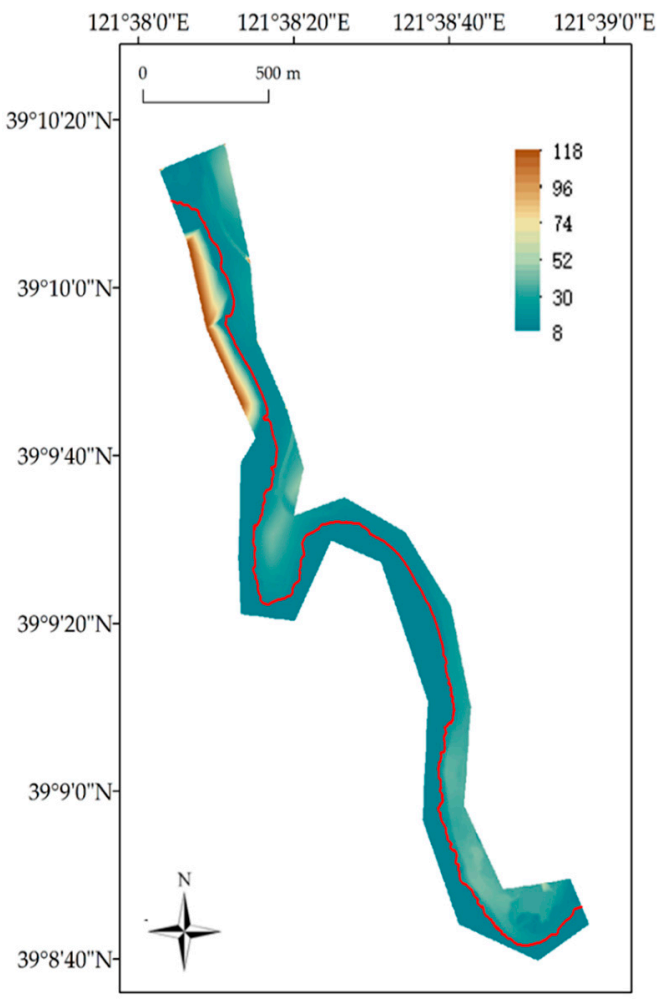

(b)

Figure 11. Digital elevation models (DEMs) and coastlines obtained in LN-A (a) and LN-B (b).

\subsection{Coastline Determination}

Using ArcGIS software, the determined MHWS along the coast zone is plotted on the coastal DEM in accordance with the elevation change, and the determinations of the coastline in the two survey areas are realized. In addition, the superimposed display of the coastlines of the two survey areas on their respective DEMs is shown in Figure 11.

\subsection{Evaluation}

As shown in Figure 12, we can see two clear blue lines in the images, which are actually marked by the coastline scoured during the last tidal period in the sea area, i.e., the dry-wet boundary clearly visible in the image, which are a little different from the standard defined coastline in the horizontal position. The trace line extraction is mainly obtained by using the characteristics of the obvious difference of the gray levels on both sides, through manual visual interpretation or automatic extraction method based on image segmentation technology. Trace lines are susceptible to non-tide factors, such as sea breezes, waves, etc., but, to a certain extent, it is similar to the trend of the standard defined coastline, and their location is similar. These characteristics can be used to judge the correctness of the standard defined coastline. By comparing with the consistency of the strict coastline location, the accuracy of the coastline can be quantitatively evaluated. 


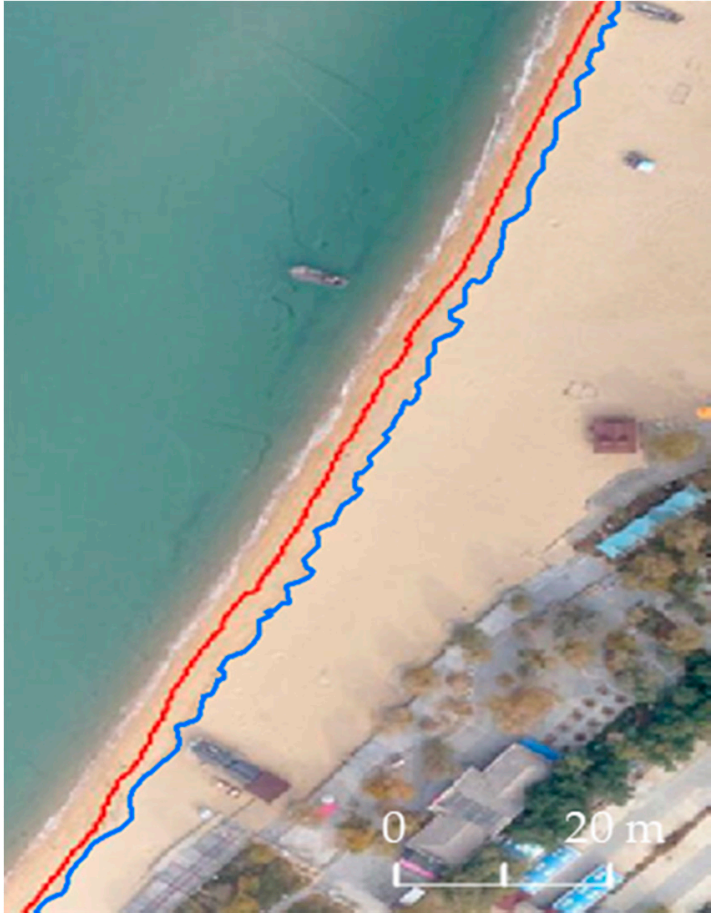

(a)

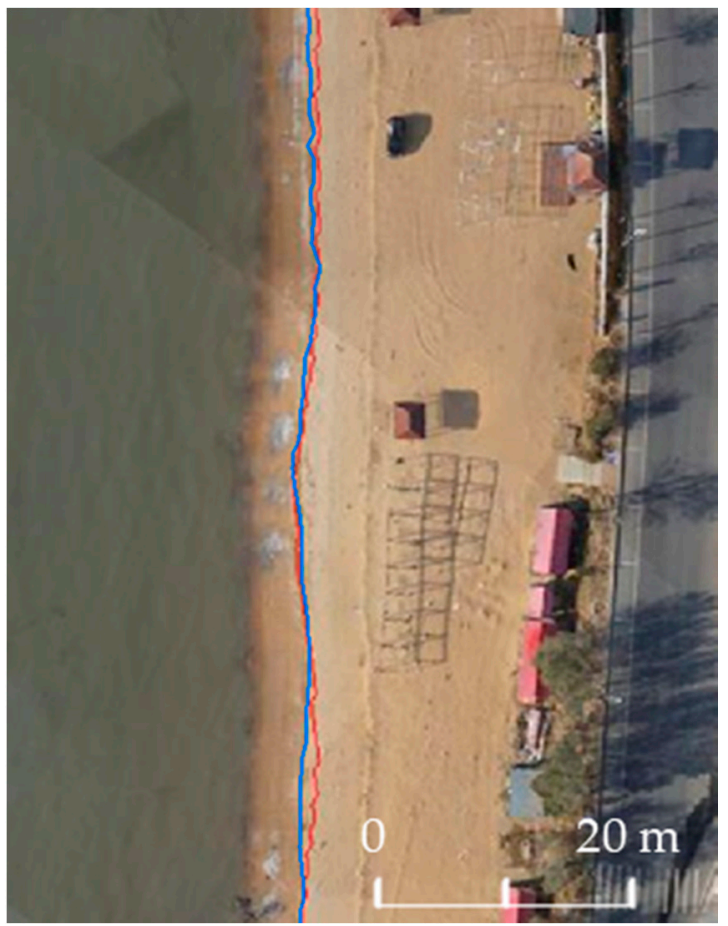

(b)

Figure 12. The extracted coastline (red) and the trace line (blue) in LN-A (a) and LN-B (b).

In the experiment, according to the high-precision three-dimensional scene model generated by tilt photography, the traces were picked, and 20 pairs of points were selected uniformly along the gradient direction, and the plane distance deviation and elevation deviation of the corresponding point pairs were counted. The feasibility of the proposed method was verified by qualitative and quantitative comparison between the actual trace coastline (dry-wet line) and the average high tide coastline in the three-dimensional model.

In general, there are some differences in the horizontal distance between the trace line and the extracted coastline in some parts, but, considering that the trace line is the traces formed by seawater immersion and is affected by seawater infiltration erosion, the trace line will extend to the land part, so this part of the difference is acceptable. Overall, the extracted coastlines are consistent with the traces.

Selecting 120 feature points with the interval of $5 \mathrm{~m}$ from the trace lines will give the 3D coordinates of these points from the coastal DEMs. We can also get the coordinates of corresponding to the selected points in the extracted coastline from the DEM. Taking the former as reference, the coordinate biases of these points can be calculated. The statistic results are listed in Table 2.

Table 2. Statistic parameters of extracted coastline by the proposed method in the two areas.

\begin{tabular}{ccccc}
\hline & \multicolumn{2}{c}{ Error in Liaoning-A (m) } & \multicolumn{2}{c}{ Error in Liaoning-B (m) } \\
\cline { 2 - 5 } & Plane Accuracy & Vertical Accuracy & Plane Accuracy & Vertical Accuracy \\
\hline Average & 1.137 & 0.075 & 1.171 & 0.302 \\
\hline Std. Dev. & 1.220 & 0.045 & 1.895 & 0.073 \\
\hline RMSE & 1.645 & 0.087 & 1.669 & 0.310 \\
\hline Min. & 0.000 & 0.010 & 0.490 & 0.150 \\
\hline Max. & 4.420 & 0.160 & 3.360 & 0.450 \\
\hline
\end{tabular}


The following conclusions can be drawn out from Table 2, Figures 7 and 8.

1. The standard deviations of plan coordinates and elevation are less than $1.9 \mathrm{~m}$ and $0.1 \mathrm{~m}$.

2. The trace line and the extracted coastline have relatively large deviations but within an acceptable range in area A, while basically consistent in area B (Figure 12). The study believes that it is related to the slope difference on the beach. The difference in the plane position of the large slope is small and, in the flat areas, is large. For the same reason, the statistic result of area A is better than that of area B.

3. The dry-wet line is just an instantaneous shoreline, while the MHWS line is a stable shoreline. At the same time, because the trace line is easily interfered by natural conditions (wind, waves, etc.), we should try our best to ensure its accuracy during aerial photography; generally, we can only use the instantaneous shoreline as an auxiliary evaluation criterion. As long as the trace line is basically consistent with the coastline obtained by the proposed method, and the trend is roughly the same, the extracted coastline can be considered effective.

\section{Discussion}

\subsection{Comparison with Existing Methods}

Remote sensing observation techniques for detecting and monitoring coastline mainly include satellite imagery [11-14], aerial photography [48,49], airborne LiDAR [15,23], terrestrial LiDAR [50,51], UAV vertical photogrammetry [22-31], and UAV tilt photogrammetry. Lin et al. compared these existing techniques and drew the conclusion that the coastline monitoring by LiDAR and photogrammetry has higher accuracy than that by the image due to the image resolution and the coastal environment. The accuracy of the former is at the centimeter level, while the latter is at the meter level [22].

However, the accuracy of photogrammetry is easily affected by the shooting environment. When there are large water areas in the measurement area, the accuracy of image matching will be seriously reduced [21]. Table 3 compares the accuracy of using photogrammetry to monitor the coastline in recent years. According to the coverage of the water area in the shooting area, they are divided into two types: land survey and water survey. It can be found that: the precision of land survey ranges in $0.02-0.05 \mathrm{~m}$ and is higher than that of water survey, which is consistent with the results of Lin et al. [22]. The accuracy of water survey is around $10 \mathrm{~cm}$ due to the image matching [22,24-28]. Based on the above, the proposed method adds the principle of consistent elevation of static water surface to the constraints of aerial triangulation, combines with the instantaneous tidal level information, significantly improves the vertical accuracy, and obtains accuracy better than $6 \mathrm{~cm}$ in coastal measurement.

Generally, the tidal level in a measurement area is forecasted by the tidal model, and the forecast accuracy is about $20-30 \mathrm{~cm}$. In the proposed method, the tidal model is correct by the GNSS tidal level, and the real-time tidal level with $5 \mathrm{~cm}$ was obtained in the applications. Therefore, the proposed tidal acquisition improves the accuracy of the coastline determination relative to the tidal forecast.

Airborne LiDAR has the unique advantages in the measuring accuracy and anti-interference [50]. However, LiDAR may become inefficient in measuring swamps, cliffs, islands, large reefs, etc., by people or vehicles. Besides, the high price and heavy weight also limit the applications of LiDAR in the coastal zone [51-53]. And because the mode of point cloud scanning is adopted, different from the mode image by image shooting adopted by photogrammetry technology, it undoubtedly takes more time to measure the terrain in the same area [22].

The above analysis shows that the proposed method provides an accurate, low-price, efficient way to determine coastline and is an efficient supplement to these existing coastline determination methods. 
Table 3. Accuracy comparison of unmanned aerial vehicle (UAV) photogrammetry methods for coastline monitoring

\begin{tabular}{|c|c|c|c|c|}
\hline Technique & Method & Point Survey Instrument & Accuracy (z) & References \\
\hline \multirow{2}{*}{ Method of this article } & $\begin{array}{l}\text { Conventional } \mathrm{UAV}^{1} \text { tilt } \\
\text { photogrammetry }\end{array}$ & GNSS-RTK $^{2}$ & $0.10-0.12 \mathrm{~m}$ & \multirow[t]{2}{*}{$(2020)$} \\
\hline & $\begin{array}{l}\text { Waterline-Constraint UAV tilt } \\
\text { photogrammetry }\end{array}$ & GNSS-RTK & $0.06 \mathrm{~m}$ & \\
\hline \multirow{7}{*}{$\begin{array}{l}\text { UAV vertical photogrammetry } \\
\text { (partial water survey) }\end{array}$} & $\begin{array}{c}\text { Coupling method of } \mathrm{UAS}^{3} \text { and } \\
\text { mobile laser scanning }\end{array}$ & $\operatorname{LiDAR}^{4}$ & $0.09-0.15 \mathrm{~m}$ & $\begin{array}{l}\text { Nahon et al. [26] } \\
\text { (2019) }\end{array}$ \\
\hline & $\begin{array}{l}\text { Conventional UAV } \\
\text { photogrammetry }\end{array}$ & GNSS-RTK & $0.06-0.43 \mathrm{~m}$ & $\begin{array}{l}\text { Lowe et al. [28] } \\
\qquad(2019)\end{array}$ \\
\hline & $\begin{array}{l}\text { Conventional UAV } \\
\text { photogrammetry }\end{array}$ & GNSS-RTK & $0.06-0.10 \mathrm{~m}$ & $\begin{array}{l}\text { Lin et al. [22] } \\
\quad(2019)\end{array}$ \\
\hline & $\begin{array}{c}\text { TLS }^{5} \text { and SfM } \\
\text { techniques }\end{array}$ & GNSS-RTK & $0.17 \mathrm{~m}$ & $\begin{array}{c}\text { Guisado-Pintado et al. [27] } \\
\text { (2018) }\end{array}$ \\
\hline & $\begin{array}{l}\text { Conventional UAV } \\
\text { photogrammetry }\end{array}$ & GNSS-RTK & $0.13 \mathrm{~m}$ & $\begin{array}{c}\text { Scarelli et al. [25] } \\
\text { (2016) }\end{array}$ \\
\hline & $\begin{array}{l}\text { Conventional UAV } \\
\text { photogrammetry }\end{array}$ & GNSS-RTK & $0.10 \mathrm{~m}$ & $\begin{array}{l}\text { Goncalves et al. [21] } \\
\text { (2015) }\end{array}$ \\
\hline & $\begin{array}{l}\text { Photogrammetry with } \\
\text { multi-beam data }\end{array}$ & GNSS-RTK & $0.12 \mathrm{~m}$ & $\begin{array}{l}\text { Casella et al. [24] } \\
\text { (2014) }\end{array}$ \\
\hline \multirow{3}{*}{$\begin{array}{l}\text { UAV vertical } \\
\text { photogrammetry(land survey) }\end{array}$} & $\begin{array}{l}\text { Conventional UAV } \\
\text { photogrammetry }\end{array}$ & GNSS-RTK & $0.05 \mathrm{~m}$ & $\begin{array}{c}\text { Casella et al. [29] } \\
\text { (2020) }\end{array}$ \\
\hline & $\begin{array}{l}\text { Conventional UAV } \\
\text { photogrammetry }\end{array}$ & GNSS-RTK & $0.02 \mathrm{~m}$ & $\begin{array}{l}\text { Pitman et al. [30] } \\
\text { (2019) }\end{array}$ \\
\hline & $\operatorname{PSInSAR}^{7}$ and UAV & GNSS-RTK & $0.05 \mathrm{~m}$ & $\begin{array}{l}\text { Mateos et al. [31] } \\
\text { (2017) }\end{array}$ \\
\hline
\end{tabular}

Structure from Motion; ${ }^{7}$ Persistent Scatterer Interferometric Synthetic Aperture Radar. 


\subsection{Accuracy Impact Analysis}

The proposed method for coastline extraction includes UAV tilt photogrammetry measurement and data processing, the determination of MHWS and waterline, and coastline extraction. Each step in the process directly affects the accuracy of the coastline extraction.

According to the principle of tilt photogrammetry and data processing, the factors that affect the quality of tilt photogrammetry are mainly, aerial triangulation, shadow, tidal level changes, coastal terrain texture (poor features and water surface), human error factors in data processing, abrupt terrain, etc. To obtain a high-precision DEM in the coastal zone, a high-performance camera and a stable drone should be selected. Besides, it is necessary to carry out the tilt photogrammetry measurement during the windless, high visibility, less shadow imaging, ebb tide, or preferably low tide periods, which help to reduce image shadows and increase the texture characteristics of the image.

A high precision POS system is needed, and a number of ground control points should be evenly laid along the topographic trend. Among them, the control points should be increased in areas with poor characteristics and large proportion of water surface. In the design of the route, the public coverage between the voyages in the rich characteristic areas is reduced, and the public coverage between the poor characteristic voyages is increased, which can significantly improve the accuracy and efficiency of the acquisition of the coastal terrain.

In the process of aerial triangulation, the water level control conditions and the tidal constraints can be added to participate in the bundle block adjustment. Assuming that the water surface points in the small area are equal in elevation, then the vertical accuracy of aerial triangulation can be significantly improved.

The generation of DEM is easily disturbed by natural and human factors. The aquaculture land, embankment, artificial beach, other kinds of human buildings and natural vegetation, cliff, and so on along the coast will lead to steep change (sudden rise or fall), destroying the smooth change of DEM. Therefore, it is necessary to repair the original terrain artificially, fill the depression area, and level the protruding area. For the cliff, the terrain can be extended according to the existing slope and, finally, make the DEM terrain become natural and smooth.

The main factors affecting the accuracy of MHWS are the length of tidal time series, the number of tidal components, the accuracy of tidal models and the local tidal properties. When there are long-term tidal stations in the survey area, it is suggested that at least one year's tidal level data should be used and at least 13 tidal components should be selected for tidal harmonic analysis. When there is no multi-year tidal level data available, the tidal information of long-term tidal stations near the measured waters can be used to calculate and transmit, and attention should be paid to the similarities of the tidal properties. For the problems that the surveyed area is far from the long-term tidal gauges, a refinement of global ocean tidal model is necessary to get high-precise tidal model, as well as MHWS. To conveniently get the instantaneous water surface of a coastal zone, GNSS buoy is needed in the acquisition of tidal level.

Being influenced by various types of land features, a large number of "false coastlines" will be extracted and need to be screened manually. Subjectivity of operators, different production methods and different parameter settings will affect the accuracy of the coastline. This problem can be weakened with the development of data processing ability of operators. When there are a large number of identifiable trace shorelines in the shooting area, we can consider the use of obvious trace lines combined with this method to synthesize coastline extraction.

\section{Conclusions}

The coastline determination method proposed in this paper has the characteristics of low cost, high efficiency, and high precision and can produce high resolution three-dimensional solid model to extract the traces of long-term erosion of sea water. It can replace the current manual measurement method, improve the objectivity of accuracy indicators, reduce the workload of field work, and can be used for rapid extraction and change monitoring of the coastline. The constraint of waterline 
height provided by GNSS tidal level is efficient for improving the accuracy of the coastal DEM when the accuracy of the tilt photogrammetry is limited in a poor-characteristic coastal zone. The global tidal ocean model provides a good way to get the mean high tide surface at the coastal zone without long-term tidal gauges, thus guaranteeing the determination of the coastline by the proposed method in any location.

To get high-accuracy coastal DEM, the tilt photography requires high-precision equipment, such as high-resolution camera, high-precision anti-shake system, POS, and so on. Besides, ideal meteorological condition, such as light, wind speed, flight time, and route, are also required. Moreover, it is recommended to use significant trace line as constraint in the bundle block adjustment to improve the accuracy of the coastal DEM and coastline.

Author Contributions: Conceptualization, C.H., J.Z. and H.Z.; Data curation, C.H.; Formal analysis, J.Z. and H.Z.; Investigation, C.H. and J.Z.; Methodology, C.H., J.Z. and H.Z.; Software, C.H.; Validation, C.H. and J.Z.; Writing-original draft, C.H.; Writing—review \& editing, J.Z. and H.Z. All authors have read and agreed to the published version of the manuscript.

Funding: This research was supported in part by the National Natural Science Foundation of China under Grant 41576107, in part by the National Natural Science Foundation of China under Grant 41376109 and in part by the National Key R\&D Program of China under Grant 2016YFB0501703.

Acknowledgments: The authors would like to thank the editors and anonymous reviewers for their comments and suggestions.

Conflicts of Interest: The authors declare no conflict of interest.

\section{References}

1. Gunawan, I. Typical Geographic Information System (GIS) Applications for Coastal Resources Management in Indonesia. Indones. J. Coast. Mar. Resour. Manag. 1998, 1, 1-12.

2. Phillips, M.R.; Jones, A.L. Erosion and tourism infrastructure in the coastal zone: Problems, consequences and management. Tour. Manag. 2006, 27, 517-524. [CrossRef]

3. Wahl, T.; Haigh, I.D.; Woodworth, P.L.; Albrecht, F.; Dillingh, D.; Jensen, J.; Nicholls, R.J.; Weisse, R.; Wöppelmann, G. Observed mean sea level changes around the North Sea coastline from 1800 to present. Earth-Sci. Rev. 2013, 124, 51-67. [CrossRef]

4. Parker, A.; Saleem, M.S.; Lawson, M. Sea-level trend analysis for coastal management. Ocean Coast. Manag. 2013, 73, 63-81. [CrossRef]

5. Gornitz, V. Global coastal hazards from future sea-level rise. Glob. Planet. Chang. 1991, 89, $379-398$. [CrossRef]

6. Thieler, E.R.; Hammar-Klose, E.S. National assessment of coastal vulnerability to sea-level rise; U.S. Atlantic Coast. Open File Rep. 1999, 1, 99-593.

7. Karymbalis, E.; Chalkias, C.; Ferentinou, M.; Chalkias, G.; Magklara, M. Assessment of the sensitivity of salamina (saronic gulf) and elafonissos (lakonic gulf) islands to sea-level rise. J. Coast. Res. 2014, 70, 378-384. [CrossRef]

8. Pendleton, E.A.; Thieler, E.R.; Williams, S.J. Coastal vulnerability assessment of cape hatteras national seashore (CAHA) to sea-level rise. In USGS Open File Report; US Geological Society: Reston, VA, USA, 2008.

9. Short, A.D.; Trembanis, A.C. Decadal scale patterns in beach oscillation and rotation Narrabeen Beach, Australia-Time series, PCA and wavelet analysis. J. Coast. Res. 2004, 20, 523-532. [CrossRef]

10. Harley, M.D.; Turner, I.L.; Short, A.; Ranasinghe, R. Assessment and integration of conventional, RTK-GPS and image-derived beach survey methods for daily to decadal coastal monitoring. Coast. Eng. 2011, 58, 194-205. [CrossRef]

11. Ryu, J.H.; Won, J.S.; Min, K.D. Waterline extraction from Landsat TM data in a tidal flat: A case study in Gomso Bay, Korea. Remote Sens. Environ. 2002, 83, 442-456. [CrossRef]

12. Overton, M.F.; Grenier, R.R., Jr.; Judge, E.K.; Fisher, J.S. Identification and analysis of coastal erosion hazard areas: Dare and Brunswick Counties, North Carolina. J. Coast. Res. 1999, 28, 69-84. 
13. Niedermeier, A.; Lehner, S.; Sanden, J.V.D. Monitoring big river estuaries using SAR images. In Proceedings of the IEEE International Geoscience \& Remote Sensing Symposium, Sydney, Australia, 9-13 July 2001; IEEE: New York, NY, USA, 2001.

14. Marfai, M.A.; Almohammad, H.; Dey, S.; Susanto, B.; King, L. Coastal dynamic and shoreline mapping: Multi-sources spatial data analysis in Semarang Indonesia. Environ. Monit. Assess. 2008, 142, 297-308. [CrossRef] [PubMed]

15. Stockdonf, H.F.; Sallenger, A.H., Jr.; List, J.H.; Holman, R.A. Estimation of shoreline position and change using airborne topographic lidar data. J. Coast. Res. 2002, 18, 502-513.

16. Ruggiero, P.; Kaminsky, G.M.; Gelfenbaum, G. Linking proxy-based and datum-based shorelines on a high-energy coastline: Implications for shoreline change analyses. J. Coast. Res. 2003, 38, 57-82.

17. Chen, W.; Chang, H. Estimation of shoreline position and change from satellite images considering tidal variation. Estuar. Coast. Shelf Sci. 2009, 84, 54-60. [CrossRef]

18. Yousef, A.H.; Iftekharuddin, K.M.; Karim, M.A. Shoreline extraction from light detection and ranging digital elevation model data and aerial images. Opt. Eng. 2013, 53, 011006. [CrossRef]

19. Liu, Z.; Li, F.; Li, N.; Wang, R.; Zhang, H. A novel region-merging approach for coastline extraction from sentinel-1A IW mode SAR imagery. IEEE Geosci. Remote Sens. Lett. 2016, 13, 324-328. [CrossRef]

20. Turner, I.L.; Harley, M.D.; Short, A.D.; Simmons, J.A.; Bracs, M.A.; Phillips, M.S.; Splinter, K.D. A multi-decade dataset of monthly beach profile surveys and inshore wave forcing at Narrabeen, Australia. Sci. Data 2016, 3, 160024. [CrossRef]

21. Gonçalves, J.A.; Henriques, R. UAV photogrammetry for topographic monitoring of coastal areas. Isprs J. Photogramm. Remote Sens. 2015, 104, 101-111. [CrossRef]

22. Lin, Y.-C.; Cheng, Y.-T.; Zhou, T.; Ravi, R.; Hasheminasab, S.M.; Flatt, J.E.; Troy, C.; Habib, A. Evaluation of UAV LiDAR for mapping coastal environments. Remote Sens. 2019, 11, 2893. [CrossRef]

23. Tamura, T.; Oliver, T.S.N.; Cunningham, A.C.; Woodroffe, C.D. Recurrence of extreme coastal erosion in SE Australia beyond historical timescales inferred from beach ridge morphostratigraphy. Geophys. Res. Lett. 2019, 46, 4705-4714. [CrossRef]

24. Casella, E.; Rovere, A.; Pedroncini, A.; Mucerino, L.; Casella, M.; Cusati, L.A.; Vacchi, M.; Ferrari, M.; Firpo, M. Study of wave runup using numerical models and low-altitude aerial photogrammetry: A tool for coastal management. Estuar. Coast. Shelf Sci. 2014, 149, 160-167. [CrossRef]

25. Scarelli, F.; Cantelli, L.; Barboza, E.G.; de Camara Rosa, M.L.C.; Giovanni, G. Natural and anthropogenic coastal system comparison using DSM from a low cost UAV survey (Capão Novo, RS/Brazil). J. Coast. Res. 2016, 2, 1232-1236. [CrossRef]

26. Nahon, A.; Molina, P.; Blazquez, M.; Simeon, J.; Capo, S.; Ferrero, C. Corridor mapping of sandy coastal foredunes with UAS photogrammetry and mobile laser scanning. Remote Sens. 2019, 11, 1352. [CrossRef]

27. Guisado-Pintado, E.; Jackson, D.W.T.; Rogers, D. 3D mapping efficacy of a drone and terrestrial laser scanner over a temperate beachdune zone. Geomorphology 2019, 328, 157-172. [CrossRef]

28. Lowe, M.K.; Adnan, F.A.F.; Hamylton, S.M.; Carvalho, R.C.; Woodroffe, C.D. Assessing reef-island shoreline change using UAV-derived orthomosaics and digital surface models. Drones 2019, 3, 44. [CrossRef]

29. Casella, E.; Drechsel, J.; Winter, C.; Benninghoff, M.; Rovere, A. Accuracy of sand beach topography surveying by drones and photogrammetry. Geo-Marine Lett. 2020, 40, 255-268. [CrossRef]

30. Pitman, S.J.; Hart, D.E.; Katurji, M. Application of UAV techniques to expand beach research possibilities: A case study of coarse clastic beach cusps. Cont. Shelf Res. 2019, 184, 44-53. [CrossRef]

31. Mateos, R.M.; Azanon, J.M.; Roldan, F.J.; Notti, D.; Pérez-Peña, V.; Galve, J.P.; Pérez-García, J.L.; Colomo, C.M.; Gómez-López, J.M.; Montserrat, O.; et al. The combined use of PSInSAR and UAV photogrammetry techniques for the analysis of the kinematics of a coastal landslide affecting an urban area (SE Spain). Landslides 2017, 14, 743-754. [CrossRef]

32. Boak, E.H.; Turner, I.L. Shoreline definition and detection: A review. J. Coast. Res. 2005, 21, 688-703. [CrossRef]

33. Li, R.; Ma, R.; Di, K. Digital tide-coordinated shoreline. Mar. Geod. 2002, 25, 27-36. [CrossRef]

34. Luque, I.F.; Aguilar Torres, F.J.; Aguilar Torres, M.A.; Pérez-García, J.L.; Arenas, A.L. A new, robust, and accurate method to extract tide-coordinated shorelines from coastal elevation models. J. Coast. Res. 2011, 28, 683-699. [CrossRef] 
35. Sánchez, J.M.; Izco, J.; Medrano, M. Relationships between vegetation zonation and altitude in a salt-marsh system in northwest Spain. J. Veg. Sci. 1996, 7, 695-702. [CrossRef]

36. Stammer, D.; Ray, R.D.; Andersen, O.B.; Arbic, B.K.; Bosch, W.; Carrere, L.; Cheng, Y.; Chinn, D.S.; Dushaw, B.D.; Egbert, G.D.; et al. Accuracy assessment of global barotropic ocean tide models. Rev. Geophys. 2014, 52, 243-282. [CrossRef]

37. Cheng, Y.; Andersen, O.B. Multimission empirical ocean tide modeling for shallow waters and polar seas. J. Geophys. Res. Ocean. 2011, 116, C11001. [CrossRef]

38. Padman, L.; Erofeeva, S. A barotropic inverse tidal model for the Arctic Ocean. Geophys. Res. Lett. 2004, 31, L02303. [CrossRef]

39. Xu, J.; Bao, J.; Liu, Y.; YU, C.X. Research on the feasibility of water level control based on tide model. Hydrogr. Surv. Charting 2011, 31, 8-12.

40. Pawlowicz, R.; Beardsley, B.; Lentz, S. Classical tidal harmonic analysis including error estimates in MATLAB using T_TIDE. Comput. Geosci. 2002, 28, 929-937. [CrossRef]

41. Gill, S.K.; Schultz, J.R. Tidal Datums and Their Applications; NOAA: Washington, DC, USA, 2001.

42. Faragher, R.M. Understanding the basis of the kalman filter via a simple and intuitive derivation [lecture notes]. IEEE Signal Process. Mag. 2012, 29, 128-132. [CrossRef]

43. Zhao, J.; Clarke, J.E.; Brucker, S.; Duffy, G.P. On the fly GPS tide measurement along the Saint John River. Int. Hydrogr. Rev. 2004, 5, 48-58.

44. Frueh, C.; Sammon, R.; Zakhor, A. Automated texture mapping of 3D city models with oblique aerial imagery. In Proceedings of the 2nd International Symposium on 3D Data Processing, Visualization and Transmission, Thessaloniki, Greece, 6-9 September 2004; IEEE: New York, NY, USA, 2004.

45. Petrie, G. Systematic oblique aerial photography using multiple digital cameras. Photogramm. Eng. Remote Sens. 2009, 75, 102-107.

46. Kerstinga, A.P.; Friess, P. Post-mission quality assurance procedure for survey-grade mobile mapping systems. ISPRS Int. Arch. Photogramm. Remote Sens. Spat. Inf. Sci. 2016, XLI-B1, 647-652. [CrossRef]

47. Liu, H.; Sherman, D.; Gu, S. Automated extraction of shorelines from airborne light detection and ranging data and accuracy assessment based on Monte Carlo simulation. J. Coast. Res. 2007, 23, 1359-1369. [CrossRef]

48. Deis, D.R.; Mendelssohn, I.A.; Fleeger, J.W.; Bourgoin, S.M.; Lin, Q. Legacy effects of Hurricane Katrina influenced marsh shoreline erosion following the Deepwater Horizon oil spill. Sci. Total Environ. 2019, 672, 456-467. [CrossRef] [PubMed]

49. Eulie, D.O.; Corbett, D.R.; Walsh, J.P. Shoreline erosion and decadal sediment accumulation in the Tar-Pamlico estuary, North Carolina, USA: A source-to-sink analysis. Estuar. Coast. ShelfSci. 2018, 202, 246-258. [CrossRef]

50. Lee, I.C.; Wu, B.; Li, R. Shoreline extraction from the integration of lidar point cloud data and aerial orthophotos using mean-shift segmentation. In Proceedings of the ASPRS 2009 Annual Conference, Baltimore, MD, USA, 9-13 March 2009.

51. Limber, P.W.; List, J.H.; Warren, J.D.; Farris, A.S.; Weber, K.M. Using topographic lidar data to delineate the North Carolina shoreline. In Proceedings of the Coastal Sediments' 07, New Orleans, LA, USA, 13-17 May 2007; ASCE: Reston, VA, USA, 2007; pp. 1837-1850.

52. Salach, A.; Bakula, K.; Pilarska, M.; Ostrowaki, W.; Gorski, K.; Kurczynski, Z. Accuracy assessment of point clouds from LiDAR and dense image matching acquired using the UAV platform for DTM creation. ISPRS Int. J. Geo-Inf. 2018, 7, 342. [CrossRef]

53. Weber, K.M.; List, J.H.; Morgan, K.L.M. An operational mean high water datum for determination of shoreline position from topographic Lidar data. Arch. Biochem. Biophys. 2005, 202, 565-572.

(C) 2020 by the authors. Licensee MDPI, Basel, Switzerland. This article is an open access article distributed under the terms and conditions of the Creative Commons Attribution (CC BY) license (http://creativecommons.org/licenses/by/4.0/). 